US Army Corps

of Engineers ${ }_{\circledast}$

Engineer Research and

Development Center

Engineering for Polar Operations, Logistics, and Research (EPOLAR)

\title{
Fenton's Reagent Treatability Study for Hydrocarbon-Contaminated Soils, McMurdo Station, Antarctica
}

Samuel A. Beal, Ashley M. Mossell, Rosa T. Affleck,

May 2020 Jay L. Clausen, and Nathan D. Williams

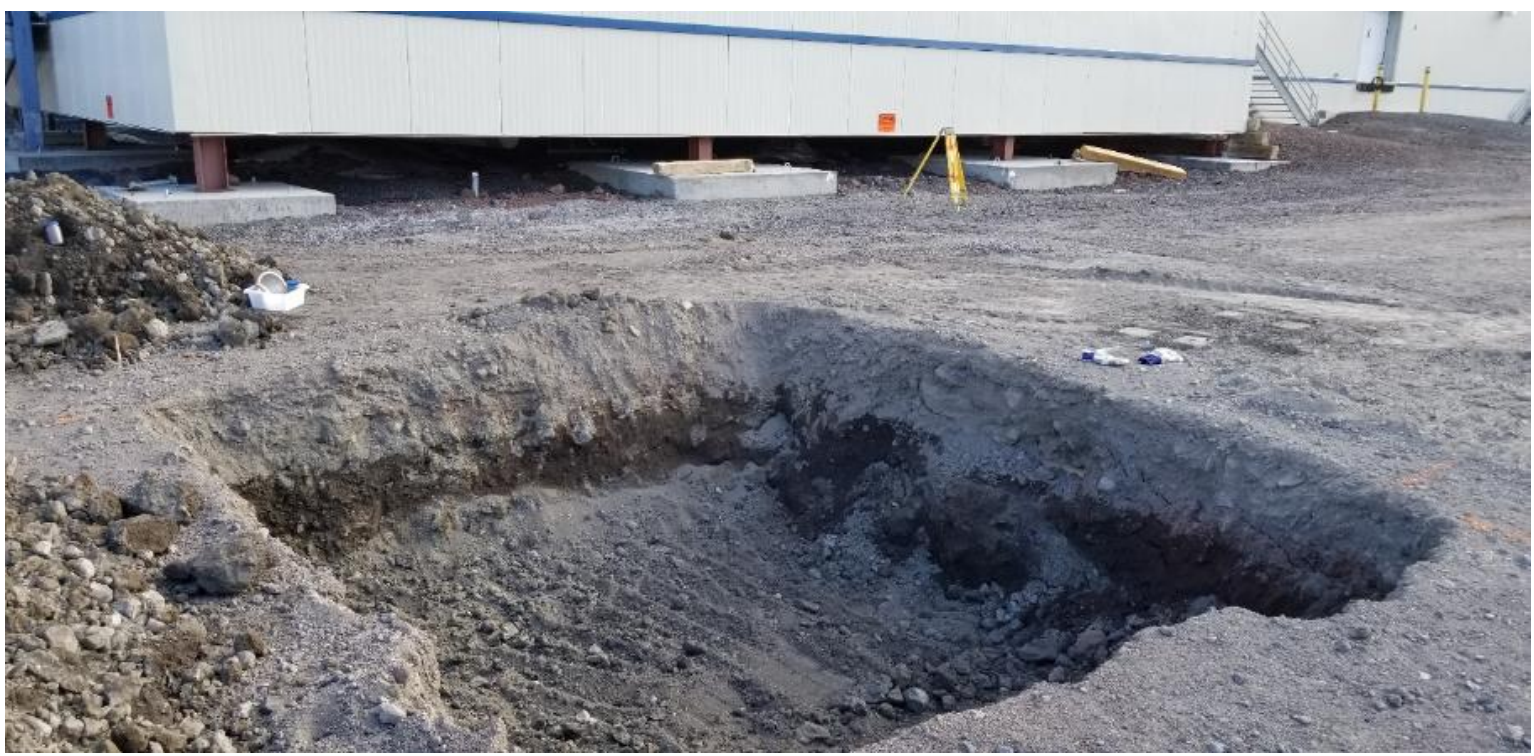


The U.S. Army Engineer Research and Development Center (ERDC) solves the nation's toughest engineering and environmental challenges. ERDC develops innovative solutions in civil and military engineering, geospatial sciences, water resources, and environmental sciences for the Army, the Department of Defense, civilian agencies, and our nation's public good. Find out more at www.erdc.usace.army.mil.

To search for other technical reports published by ERDC, visit the ERDC online library at http://acwc.sdp.sirsi.net/client/default. 
May 2020

\section{Fenton's Reagent Treatability Study for Hydrocarbon-Contaminated Soils, McMurdo Station, Antarctica}

Samuel A. Beal, Ashley M. Mossell, Rosa T. Affleck, and Jay L. Clausen

U.S. Army Engineer Research and Development Center (ERDC)

Cold Regions Research and Engineering Laboratory (CRREL)

72 Lyme Road

Hanover, NH 03755-1290

Nathan D. Williams

Antarctic Support Contract

Leidos

11951 Freedom Drive

Reston, VA 20190-5640

Final Report

Approved for public release; distribution is unlimited.

Prepared for National Science Foundation

Office of Polar Programs

Antarctic Infrastructure and Logistics

2415 Eisenhower Avenue

Alexandria, VA 22314

Under Engineering for Polar Operations, Logistics, and Research (EPOLAR)

EP-ANT-18-80, “Hydrogen Peroxide / Fenton's Reagent Treatability Study of McMurdo Station Hydrocarbon-Contaminated Soil” 


\section{Abstract}

Hydrocarbon-contaminated soil is distributed heterogeneously at McMurdo Station, Antarctica, which has served for over 60 years as the logistics hub for the U.S. Antarctic Program. Here we investigated the treatability of McMurdo Station's contaminated soil with chemical oxidation. Our study collected five soil samples in 2018 and 2019, of which two contained high levels ( $>100 \mathrm{mg} / \mathrm{kg}$ ) of total petroleum hydrocarbons (TPH) suitable for the treatability study. One soil (ITC) was characterized by 1250 $\mathrm{mg} / \mathrm{kg}$ of predominantly midrange (n-C8 to $\mathrm{n}-\mathrm{C} 16$ ) hydrocarbons, and the other (Soil Pile) was characterized by $3500 \mathrm{mg} / \mathrm{kg}$ of predominantly heavy molecular weight ( $>$ n-C21) hydrocarbons. We investigated the treatability of these soils with both Fenton's Reagent $\left(\mathrm{pH}<3\right.$ with $\left.\mathrm{Fe}^{2+}\right)$ and modified Fenton's Reagent (chelated $\mathrm{Fe}^{2+}$ ), each with hydrogen peroxide concentrations of $3 \%$ and $10 \%$. Soil slurries were placed on a shaker table at $100 \mathrm{rpm}$ and $4^{\circ} \mathrm{C}$ for up to 21 days. TPH concentrations were reduced by approximately 50\% for ITC; however, the oxidative treatments did not out-perform controls. All treatments and controls yielded no significant reduction in Soil Pile TPH. Poor performance by these chemical oxidation treatments indicates that remediation of hydrocarbons at these sites may require further soil processing in combination with chemical oxidation or alternative treatment technologies.

DISCLAIMER: The contents of this report are not to be used for advertising, publication, or promotional purposes. Citation of trade names does not constitute an official endorsement or approval of the use of such commercial products. All product names and trademarks cited are the property of their respective owners. The findings of this report are not to be construed as an official Department of the Army position unless so designated by other authorized documents.

DESTROY THIS REPORT WHEN NO LONGER NEEDED. DO NOT RETURN IT TO THE ORIGINATOR. 


\section{Contents}

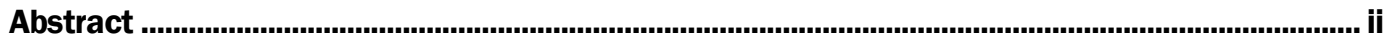

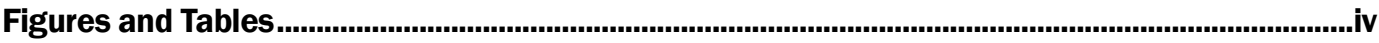

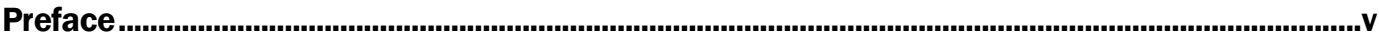

Acronyms and Abbreviations ........................................................................................................

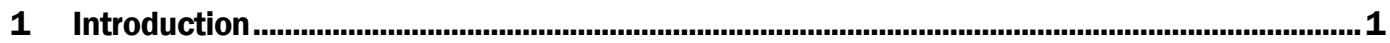

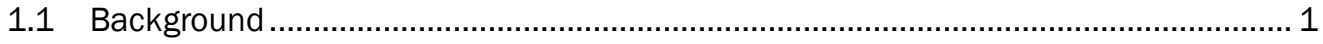

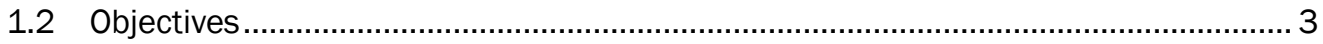

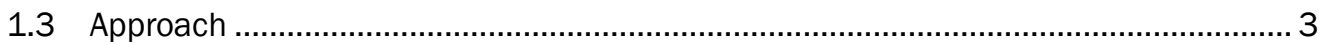

2 Methods .................................................................................................................................. 4

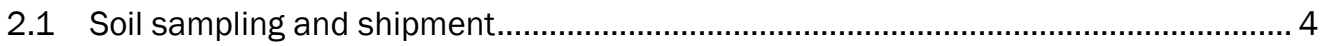

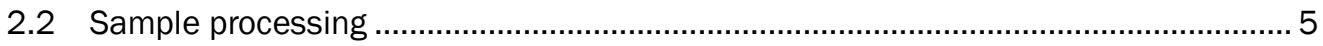

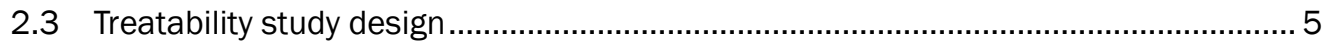

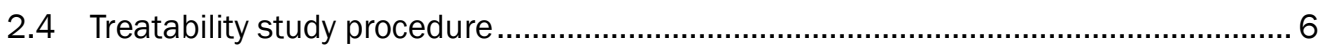

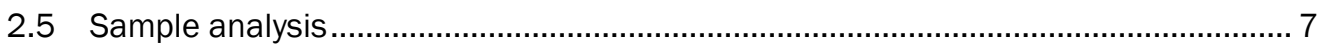

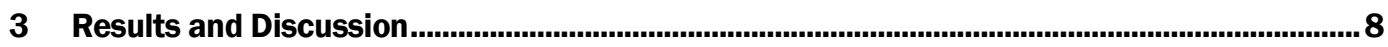

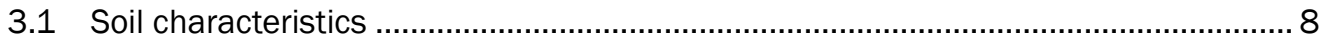

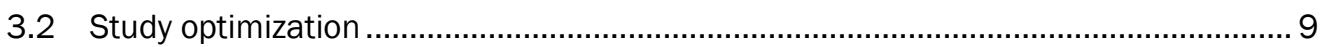

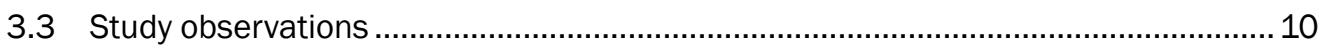

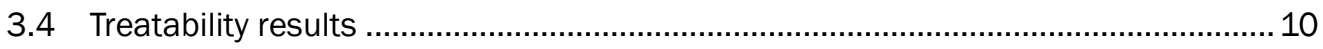

3.5 Limitations and field-scale applicability .................................................... 13

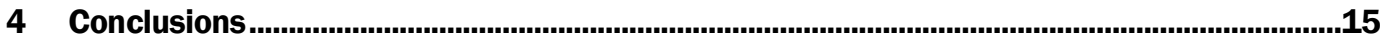

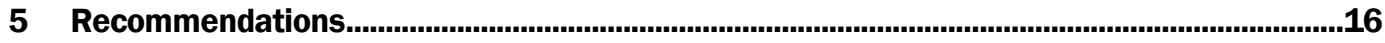

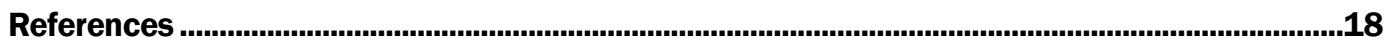

Appendix A: Supporting Figures and Data................................................................................21

Report Documentation Page 


\section{Figures and Tables}

\section{Figures}

1 Sampled sites where hydrocarbon contamination was suspected ................................... 5

2 Representative GC-FID chromatograms for ITC F1 and Soil Pile extracts. Retention times for $n$-alkane marker compounds are shown in gray................................. 9

3 Air temperatures adjacent to the experiment's shaker table during the 21day experiments. The dashed line represents the mean temperature.

$4 \quad$ Posttreatment TPH concentrations in ITC F1 and Soil Pile samples by reaction time and treatment type. The dotted lines represent mean \pm 1 standard deviation bounds of pretreatment TPH concentrations

5 Posttreatment HMW concentrations in Soil Pile samples by reaction time and treatment type. Dotted lines represent mean \pm 1 standard deviation bounds of pretreatment HMW concentrations.

A-1 GC-FID chromatograms of soil samples and the hydrocarbon standards for diesel (5000 mg/L), gasoline (500 mg/L), JP-5 (5000 mg/L), JP-8 (5000 $\mathrm{mg} / \mathrm{L}$ ), and hydraulic oil (500 mg/L). The gasoline standard signal is $5 \times$ for plotting.

A-2 Posttreatment TPH concentrations in ITC F1 samples by reaction time and treatment type. Dotted lines represent mean \pm 1 standard deviation bounds of pretreatment TPH concentrations

A-3 Posttreatment TPH concentrations in Soil Pile samples by reaction time and treatment type. Dotted lines represent mean \pm 1 standard deviation bounds of pretreatment TPH concentrations

A-4 Posttreatment HMW concentrations in Soil Pile samples by reaction time and treatment type. Dotted lines represent mean \pm 1 standard deviation bounds of pretreatment HMW concentrations.

\section{Tables}

1 Soil-sample descriptions

2 Five treatment levels used in batch experiments. Volumes of $\mathrm{pH}$ modifier were to be determined (TBD) experimentally for each soil, discussed in Section 3.2.

3 Soil particle size from sieving (whole sample) and initial TPH results for the $<2 \mathrm{~mm}$ fraction (average \pm one standard deviation) on triplicate subsamples.

$4 \quad$ Acid addition optimization results for Fenton's Reagent treatment ................................... 9

5 Treatability results for Soil Pile at room temperature and $4^{\circ} \mathrm{C}$ over 4 days ....................13

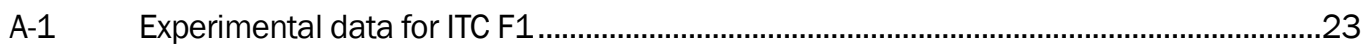

A-2 Experimental data for Soil Pile ..................................................................................2 


\section{Preface}

This study was conducted for the National Science Foundation (NSF), Office of Polar Programs (OPP), Antarctic Infrastructure and Logistics Program (AIL), under Project EP-ANT-18-80, "Hydrogen Peroxide / Fenton's Reagent Treatability Study of McMurdo Station Hydrocarbon-Contaminated Soil.” The technical monitor was Ms. Margaret Knuth, Operations Manager, NSF-OPP-AIL, U.S. Antarctic Program.

The work was performed by the Biogeochemical Sciences Branch (BSB) and the Force Projection and Sustainment Branch (FPSB) of the Research and Engineering Division, U.S. Army Engineer Research and Development Center, Cold Regions Research and Engineering Laboratory (ERDCCRREL). At the time of publication, Dr. Gina Ralph was Acting Chief, BSB; Mr. Justin Putnam was Acting Chief, FPSB; and Mr. J. D. Horne was Division Chief. The Deputy Director of ERDC-CRREL was Mr. David B. Ringelberg, and the Director was Dr. Joseph L. Corriveau.

The authors gratefully acknowledge Ms. Anne Hellie and Ms. Spring Wood, formerly with Leidos, Antarctic Support Contract (ASC), for the report on their Fenton's Reagent study on the McMurdo soil pile. The authors also acknowledge the assistance by ASC staff in collecting, packaging, and shipping samples.

COL Teresa A. Schlosser was Commander of the ERDC, and Dr. David W. Pittman was the ERDC Director. 


\section{Acronyms and Abbreviations}

AIL

ASC

BSB

CRREL

EDTA

EPOLAR

ERDC

$\mathrm{Fe}(\mathrm{II}) \mathrm{SO}_{4} \cdot 7 \mathrm{H}_{2} \mathrm{O}$

FPSB

FR

GC-FID

HMW

$\mathrm{H}_{2} \mathrm{O}_{2}$

$\mathrm{H}_{2} \mathrm{SO}_{4}$

ITC

ITC F1

MFR

NSF

OPP

ppm

rpm

TBD
Antarctic Infrastructure and Logistics Program

Antarctic Support Contract

Biogeochemical Sciences Branch

U.S. Army Cold Regions Research and Engineering Laboratory

Ethylenediaminetetraacetic Acid, a Chelate

Engineering for Polar Operations, Logistics, and Research

Engineer Research and Development Center

Iron Sulfate

Force Projection and Sustainment Branch

Fenton's Reagent

Gas Chromatography with a Flame Ionization Detector

High Molecular Weight Petroleum Compounds

Hydrogen Peroxide

Sulfuric Acid

Information Technology and Communications

Information Technology and Communications First Foundation Footer

Modified Fenton's Reagent

National Science Foundation

Office of Polar Programs

Parts per Million

Revolutions per Minute

To Be Determined 
TPH

USDA

USAP

$\mathrm{VMF}$

VMF7
Total Petroleum Hydrocarbons

U.S. Department of Agriculture

U.S. Antarctic Program

Vehicle Maintenance Facility

Vehicle Maintenance Facility Bay 7 



\section{Introduction}

\subsection{Background}

McMurdo Station, located on the Hut Point Peninsula, Ross Island, Antarctica, serves as the logistics hub for the U.S. Antarctic Program (USAP), which is managed by the National Science Foundation (NSF). McMurdo provides research and science support across the continent of Antarctica, including to Amundsen-Scott South Pole Station. McMurdo Station's existing facilities were constructed on an outcrop of barren volcanic rock modified to form a series of flat fill platforms (Affleck et al. 2017). Initially established in 1955, McMurdo Station has grown to include approximately 100 buildings, three runways, and a helicopter pad.

Soil contamination by fuel and lubricating oil spills occurs in patches across McMurdo Station. Areas of high contamination, characterized by total petroleum hydrocarbons (TPH) greater than 500 parts per million (ppm), are concentrated near fuel storage tanks (formerly used and current), refueling stations, vehicle maintenance facilities, a landfill, and vehicle parking areas (Klein et al. 2012). High molecular weight petroleum compounds (HMW) are present primarily in areas where vehicles are parked and are not associated with fuel tanks and refueling stations (Klein et al. 2012). The dominant fuels used at McMurdo since its construction have been JP-5, JP-8, AN-8 (a special low-freezing-point fuel), and MOGAS (unleaded gasoline; Klein et al. 2008; Haehnel et al. 2017). Between 2005 and 2015, USAP purchased approximately 19 million liters per year total of JP-5, AN-8, and gasoline (Haehnel et al. 2017). Unlike some other Antarctic bases, diesel is not a primary fuel at McMurdo (Aislabie et al. 2004).

The fate and transport of hydrocarbons depend on the type of fuel spilled and the soil structure. Gasoline and lighter components of the jet fuels JP5 , JP-8, and AN-8 readily volatilize at the surface and, due to their lower viscosity, are also more mobile than diesel and oils (Aislabie et al. 2004). Hydrocarbon permeation in soil overlying permafrost may be limited to the active layer, as permanently frozen soil acts as a physical barrier in the absence of any cracks or fissures (Aislabie et al. 2004). However, a suspected hydrocarbon layer in the ice-cemented substrate underneath frozen soil at McMurdo Station was identified in soil pits and cores (Affleck et al. 2017) and in ground-penetrating-radar surveys (Campbell et al. 2018). Runoff 
measured from major McMurdo drainages during a period of thaw did not yield any petroleum hydrocarbon concentrations above the detection limits (40-300 $\mu \mathrm{g} / \mathrm{L} ;{ }^{*}$ Affleck et al. 2014), which indicated contaminants were relatively adsorbed in place and minimally displaced by snowmelt.

Current building development on McMurdo station needs to manage potentially contaminated soils and to find inexpensive management solutions compared with off-site disposal (NSF 2019). Unfortunately, in cold regions like McMurdo Station, hydrocarbons can persist and accumulate over long periods of time due to low biological activity, low soil moisture, low nutrient levels, and slow reaction kinetics (Affleck et al. 2017; Aislabie et al. 2004; Eriksson et al. 2001; Klein et al. 2012). This slow natural attenuation explains elevated TPH concentrations near previously removed fuel tanks at McMurdo (Klein et al. 2012) and hydrocarbon off-gassing from soil pits (Affleck et al. 2017) and soil cores (Fenwick and Winkler 2016; Fenwick et al. 2017). At Old Casey Station, Antarctica, biodegradation stimulated with added nutrients resulted in only a $15 \%$ decrease in soil diesel concentrations (Ferguson et al. 2003).

Chemical oxidation has been a successful method for remediating petroleum-contaminated soil at more temperate locations. Though there are many chemical oxidants, Fenton's Reagent has been among the most popular. Fenton's Reagent involves the reaction of hydrogen peroxide $\left(\mathrm{H}_{2} \mathrm{O}_{2}\right)$ with $\mathrm{Fe}^{2+}$ to form the reactive hydroxyl radical and $\mathrm{Fe}^{3+}$. Classic Fenton's Reagent uses $0.03 \% \mathrm{H}_{2} \mathrm{O}_{2}$, but field applications require higher concentrations (Interstate Technology and Regulatory Council 2005). Typically, acidic conditions improve TPH degradation by reducing $\mathrm{Fe}^{3^{+}}$to the more soluble $\mathrm{Fe}^{2+}$ (Watts 1992). There have been numerous modifications to Fenton's Reagent, which in many cases use chelates to improve iron solubility and availability without the need for acidic conditions (e.g., Kakarla et al. 2002). Lab-scale studies on petroleum-contaminated soil in temperate regions typically observe 50\% or greater reduction in TPH with Fenton's Reagent and Modified Fenton's Reagent treatments (Lu et al. 2010; Mater et al. 2007; Tsai and Kao 2009).

\footnotetext{
* For a full list of the spelled-out forms of the units of measure and chemical elements used in this document, please refer to U.S. Government Publishing Office Style Manual, 31st ed. (Washington, DC: U.S Government Publishing Office, 2016), 248-252, 265, https://www.govinfo.gov/content/pkg/GPO-STYLEMANUAL-2016/pdf/GPO-STYLEMANUAL-2016.pdf.
} 
At low temperatures, decreased kinetics may inhibit Fenton's Reagent performance. However, a recent study found complete degradation with $\mathrm{H}_{2} \mathrm{O}_{2}$ treatment on Arctic soil at $4^{\circ} \mathrm{C}$ (Sherwood and Cassidy 2014). To date, only one published study has examined chemical oxidation of petroleum-contaminated soils in Antarctica. Ferguson et al. (2004) conducted a field trial on diesel-contaminated soil at Old Casey Station and did not observe any degradation using relatively concentrated $\mathrm{H}_{2} \mathrm{O}_{2}(30 \%)$.

\subsection{Objectives}

The objective of this study was to determine the effectiveness of Fenton's Reagent and Modified Fenton's Reagent in reducing TPH concentrations in petroleum-contaminated soil from McMurdo Station.

\subsection{Approach}

This study approached treatability through lab-scale tests on sampled McMurdo soils by using four different treatments and eleven time steps. This method attempted to simulate realistic remediation conditions possible at McMurdo Station by using minimal sample preparation, relatively safe-for-handling reagent concentrations, and site-relevant ambient temperatures. 


\section{Methods}

\subsection{Soil sampling and shipment}

For this study, Antarctic Support Contract collected samples from five sites at McMurdo Station in 2018 and 2019 (Table 1). Samples from two sites (Red Fines and Gray Fines) were expected to be clean as these materials are used for current construction activities. Three sites sampled had expected hydrocarbon contamination based on usage history, odor, and appearance (Figure 1). At the Vehicle Maintenance Facility (VMF), soil was collected from the surface outside Bay 7 (VMF7) where vehicle fluids may have accidentally been released. At the Information Technology and Communications (ITC) building's first foundation footer (ITC F1), suspected clean fill material was underlain by a darker layer with a hydrocarbon odor-the sample was collected from the darker layer. The Soil Pile was composed of material collected from spills that occurred during 2018 and early 2019. Duplicate samples were collected using a metal scoop and $1 \mathrm{~L}$ glass jars with polytetrafluoroethylene-lined caps. Sample containers were filled to have minimal headspace.

The VMF, Red Fines, and Gray Fines samples were initially stored in an unrefrigerated storage container at McMurdo Station and may have experienced infrequent periods of temperatures above $10^{\circ} \mathrm{C}$ in austral summer months. The ITC F1 and Soil Pile samples were stored in a $-20^{\circ} \mathrm{C}$ freezer upon collection. All samples were shipped frozen, to minimize in-transport degradation, from McMurdo to the U.S. Army Cold Regions Research and Engineering Laboratory (CRREL) via Port Hueneme, California. Samples arrived at CRREL on 4 April 2019 and were immediately placed in a cold room at approximately $-20^{\circ} \mathrm{C}$.

Table 1. Soil-sample descriptions.

\begin{tabular}{|l|l|l|}
\hline \multicolumn{1}{|c|}{ Sample } & \multicolumn{1}{c|}{$\begin{array}{c}\text { Sampling } \\
\text { Date }\end{array}$} & \multicolumn{1}{c|}{ Description } \\
\hline VMF7 & $2 / 13 / 2018$ & Location outside Bay 7 with historic spills; no odor \\
\hline Red Fines & $2 / 13 / 2018$ & Clean red fines used for construction and operations \\
\hline Gray Fines & $2 / 13 / 2018$ & Clean gray fines used for construction and operations \\
\hline ITC F1 & $1 / 9 / 2019$ & $\begin{array}{l}\text { ITC First Footer location near the entrance to the mechanical } \\
\text { equipment center; strong odor }\end{array}$ \\
\hline Soil Pile & $1 / 9 / 2019$ & $\begin{array}{l}\text { Soil collected from station spills during the 2018-2019 season; } \\
\text { light odor, may contain glycol }\end{array}$ \\
\hline
\end{tabular}


Figure 1. Sampled sites where hydrocarbon contamination was suspected.
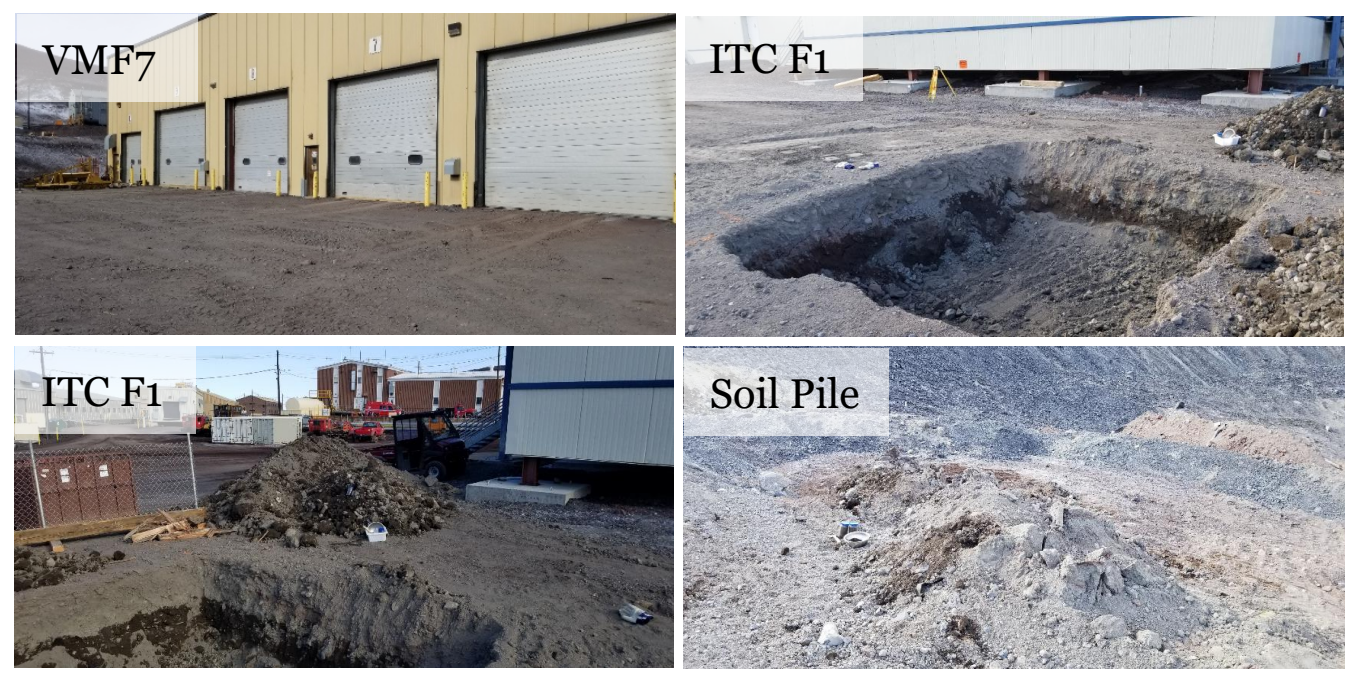

\subsection{Sample processing}

We removed soil samples from the cold room and transferred them to refrigerators $\left(4^{\circ} \mathrm{C}\right)$ to thaw for two days. Thawing was required to disaggregate soil grains and to enable representative subsampling of the material. Entire thawed soil samples were passed through a $2 \mathrm{~mm}$ stainless steel sieve in a refrigerated room $\left(\sim 4^{\circ} \mathrm{C}\right)$. The two sieve fractions were isolated and stored in separate glass jars. Approximately $10 \mathrm{~g}$ subsamples were collected from thawed $<2 \mathrm{~mm}$ soil by spreading the sample out to an approximately $1 \mathrm{~cm}$ deep layer on aluminum foil in a fume hood and collecting 20-40 evenly spaced increments into $40 \mathrm{~mL}$ vials.

\subsection{Treatability study design}

The study simulated remediation conditions that would be relatively feasible to create at McMurdo Station during austral summer, including nonhomogenized soil, low reagent-to-soil ratios (1:2), safe-to-handle reagents, minor amounts of agitation, and a cool temperature $\left(\sim 4^{\circ} \mathrm{C}\right)$. The studied temperature was chosen to ensure reagents remained in the liquid state, particularly the iron catalyst. The freezing point of $\mathrm{H}_{2} \mathrm{O}_{2}$ varies significantly with its concentration, for instance $-2^{\circ} \mathrm{C}$ at $3 \mathrm{wt} \%,-6^{\circ} \mathrm{C}$ at $9 \mathrm{wt} \%$, and $-23^{\circ} \mathrm{C}$ at 28 wt\% (Foley and Giguère 1951). Our study, therefore, serves as an upper bound on degradation rates that can be achieved without intensive manipulation of soil conditions, as temperatures infrequently exceed freezing at McMurdo Station (Affleck et al. 2012). 
The experimental variables investigated in this study were five different treatments and eleven reaction time steps. The experimental treatments were determined using established guidance on chemical oxidation treatments that are feasibly implemented by remedial operators in the field (Siegrist 2010). The treatments listed in Table 2 include Fenton's Reagent (FR) at $3 \%$ and $10 \% \mathrm{H}_{2} \mathrm{O}_{2}$ (Fisher Chemical $30 \%$ Certified ACS) with $0.1 \mathrm{M}$ $\mathrm{Fe}$ as iron sulfate ( $\mathrm{Fe}(\mathrm{II}) \mathrm{SO}_{4} \cdot 7 \mathrm{H}_{2} \mathrm{O}$; Acros Organics 99+\%) and sulfuric acid $\left(\mathrm{H}_{2} \mathrm{SO}_{4}\right.$; Fisher Chemical Trace Metal Grade) to modify pH to 3. A modified Fenton's Reagent (MFR) consisted of o.1 M Fe and o.1 M EDTA* (Sigma ACS Grade 99.6\%) to chelate Fe and avoid $\mathrm{pH}$ modification, with both a low (3\%) and high (10\%) concentration of $\mathrm{H}_{2} \mathrm{O}_{2}$. MilliQ deionized water (18.2 M $\Omega$ ) was also tested as a control. Subsamples from each treatment group were sacrificed at 30 minutes, 1 hour, 2 hours, 4 hours, 8 hours, 1 day, 2 days, 4 days, 7 days, 14 days, and 21 days after treatment.

Table 2. Five treatment levels used in batch experiments. Volumes of $\mathrm{pH}$ modifier were to be determined (TBD) experimentally for each soil, discussed in Section 3.2.

\begin{tabular}{|c|c|c|c|}
\hline Treatment & Iron/Chelate & pH Modifier & Oxidizer \\
\hline FR 3\% & $2.5 \mathrm{~mL} 0.1 \mathrm{M} \mathrm{Fe}$ & $\mathrm{TBD} \mu \mathrm{L} 1 \mathrm{M} \mathrm{H}_{2} \mathrm{SO}_{4}$ & $2.5 \mathrm{~mL} 3 \% \mathrm{H}_{2} \mathrm{O}_{2}$ \\
\hline FR 10\% & $2.5 \mathrm{~mL} 0.1 \mathrm{M} \mathrm{Fe}$ & $\mathrm{TBD} \mu \mathrm{L} 1 \mathrm{M} \mathrm{H}_{2} \mathrm{SO}_{4}$ & $2.5 \mathrm{~mL} 10 \% \mathrm{H}_{2} \mathrm{O}_{2}$ \\
\hline MFR 3\% & $2.5 \mathrm{~mL} 0.1 \mathrm{M} \mathrm{Fe} / \mathrm{EDTA}$ & - & $2.5 \mathrm{~mL} \mathrm{3} \% \mathrm{H}_{2} \mathrm{O}_{2}$ \\
\hline MFR 10\% & $2.5 \mathrm{~mL} 0.1 \mathrm{M} \mathrm{Fe} / \mathrm{EDTA}$ & - & $2.5 \mathrm{~mL} 10 \% \mathrm{H}_{2} \mathrm{O}_{2}$ \\
\hline Control & - & - & $5 \mathrm{~mL}$ MilliQ \\
\hline
\end{tabular}

\subsection{Treatability study procedure}

The experiment began upon addition of treatment reagents to thawed soil subsamples ( $10 \mathrm{~g}$ ) in a fume hood. These samples were vortexed to mix the reagents and the soil slurries, then immediately moved to a cold room $\left(\sim 4^{\circ} \mathrm{C}\right)$ and placed on a shaker table at $100 \mathrm{rpm}$ (revolutions per minute). Caps were placed loosely on subsamples to allow evolved gases to vent without breaking the vials. At each time step, soil slurries were removed from shaking and extracted with $20 \mathrm{~mL}$ of $\mathrm{n}$-hexane (Fisher Chemical Optima 95\%). The extracts were vortexed for 30 seconds, centrifuged at $1000 \mathrm{rpm}$ for 1 minute, and the upper organic phase syringe filtered $(0.45$ $\mu \mathrm{m}$ Millex-FH) into autosampler vials, which were then refrigerated at approximately $4^{\circ} \mathrm{C}$ until analysis. Samples were analyzed within 3 days of extraction.

* Ethylenediaminetetraacetic acid, a chelate 
Rapid sample extraction was required to capture TPH concentrations at short time periods. Addition of anhydrous sodium sulfate was tested to chemically dry the samples and effectively stop the reaction. Approximately $12 \mathrm{~g}$ and $10 \mathrm{~g}$ of salt were required for ITC F1 and Soil Pile, respectively. However, drying created an impermeable cap that prevented hexane from interacting with the dried soil during extraction, evidenced by low TPH recoveries (<20\%). Instead, the method of rapid extraction, centrifugation, and filtration produced TPH concentrations within the subsampling variability of the raw untreated soils and was subsequently used for the treatability study.

\subsection{Sample analysis}

Sample extracts were measured for TPH by gas chromatography with a flame ionization detector (GC-FID; Agilent 6890A). The column was an Agilent HP Ultra2 $25 \mathrm{~m} \times 0.200 \mathrm{~mm}$ with $0.33 \mu \mathrm{m}$ film thickness; the injection volume was $1 \mu \mathrm{L}$; the splitless inlet was set at $285^{\circ} \mathrm{C} ; \mathrm{H}_{2}$ carrier gas was set at $2 \mathrm{~mL} / \mathrm{min}$; and the detector was set at $325^{\circ} \mathrm{C}$ with $40 \mathrm{~mL} / \mathrm{min}$ $\mathrm{H}_{2}, 450 \mathrm{~mL} / \mathrm{min}$ air, and $45 \mathrm{~mL} / \mathrm{min}_{2}$. The oven temperature program was $30^{\circ} \mathrm{C}$ from o to 3 minutes followed by a linear ramp to $300^{\circ} \mathrm{C}$ at $15^{\circ} \mathrm{C} / \mathrm{min}$ and held at $300^{\circ} \mathrm{C}$ for 5 minutes. The total run time was 26 minutes. TPH was determined by integrating the peak area from n-C8 to n-C36 retention times ( 4.72 to $25.80 \mathrm{~m}$ ) using a straight baseline. For samples containing prominent late-eluting peaks, an HMW peak (Klein et al. 2012) was also integrated from 18.8 to 21.0 minutes. Soil moisture was determined by drying subsamples at $110^{\circ} \mathrm{C}$ overnight, and concentrations were corrected to report TPH on a dry-weight basis.

Stock and spike standards combined equal parts JP-5, JP-8, unleaded gasoline, diesel fuel \#2, and hydraulic oil analytical standards (all from Restek) to a final TPH concentration of $2250 \mathrm{mg} / \mathrm{L}$. Calibration standards were made by diluting the stock standard to final concentrations ranging from 20 to $2250 \mathrm{mg} / \mathrm{L}$. A five-point calibration, a boiling point / carbon number standard (Restek; n-C6, n-C8, n-C10, n-C12, n-C16, n-C21, n-C28, n-C35, n-C36), and an independent calibration verification (Restek; JP-5, JP-8, diesel \#2) were run on the GC-FID daily with each batch of samples. 


\section{Results and Discussion}

\subsection{Soil characteristics}

All of the soils contained a dominant proportion of $>2 \mathrm{~mm}$ particle sizes (Table 3). This fraction is considered gravel and is not included in USDA (U.S. Department of Agriculture) soil characterization. Hydrocarbons are likely to reside between the larger surface area of the $(<2 \mathrm{~mm})$ soil grains, making the smaller-soil-size fraction of greater interest in this study. Further, this smaller particle size is more likely to produce subsamples with TPH concentrations that are more reproducible than those from gravel.

TPH concentrations were below the detection limit ( $40 \mathrm{mg} / \mathrm{kg}$ ) for the Red Fines and Gray Fines soils, and they were above the detection limit but relatively low for VMF7. The GC-FID chromatograms for VMF7 were generally flat for most compounds less than $\mathrm{n}-\mathrm{C} 21$ but had small late-eluting peaks characteristic of HMW at McMurdo Station (Klein et al. 2012). Soil from ITC F1 and Soil Pile contained relatively high TPH concentrations of 1250 and $3500 \mathrm{mg} / \mathrm{kg}$, respectively. GC-FID chromatograms of ITC F1 and Soil Pile highlight differing hydrocarbon sources at these sites (Figure 2). The chromatogram for ITC F1 shows a singular feature between n-C8 and $\mathrm{n}$-C16 whereas the chromatogram for Soil Pile exhibits a peak between n$\mathrm{C} 10$ and $\mathrm{n}-\mathrm{C} 16$ followed by a prominent peak between n-C21 and n-C35. The earlier peaks in both samples are consistent with jet fuels or kerosene. The later peak in Soil Pile reflects the HMW peak found across McMurdo Station near roads and parking areas and is suspected to derive from hydraulic fluid (Klein et al. 2012). The overall high TPH concentrations from ITC F1 and Soil Pile enabled these soils to be used in the treatability study, as measurable reductions in TPH would indicate successful treatment.

Table 3. Soil particle size from sieving (whole sample) and initial TPH results for the $<2 \mathrm{~mm}$ fraction (average \pm one standard deviation) on triplicate subsamples.

\begin{tabular}{|l|c|c|c|c|}
\hline \multicolumn{1}{|c|}{ Sample } & $>\mathbf{2 ~} \mathbf{~ m m ~ ( \% ) ~}$ & $<\mathbf{~ m m ~ ( \% ) ~}$ & Moisture $(\%)$ & TPH $(\mathbf{m g} / \mathbf{k g})$ \\
\hline VMF7 & 50.7 & 49.3 & 5.3 & $100 \pm 20$ \\
\hline Red Fines & 66.0 & 34.0 & - & $<40$ \\
\hline Gray Fines & 54.4 & 45.6 & - & $<40$ \\
\hline ITC F1 & 75.0 & 25.0 & 8.8 & $1250 \pm 90$ \\
\hline Soil Pile & 58.1 & 41.9 & 3.2 & $3500 \pm 300$ \\
\hline
\end{tabular}


Figure 2. Representative GC-FID chromatograms for ITC F1 and Soil Pile extracts. Retention times for n-alkane marker compounds are shown in gray.

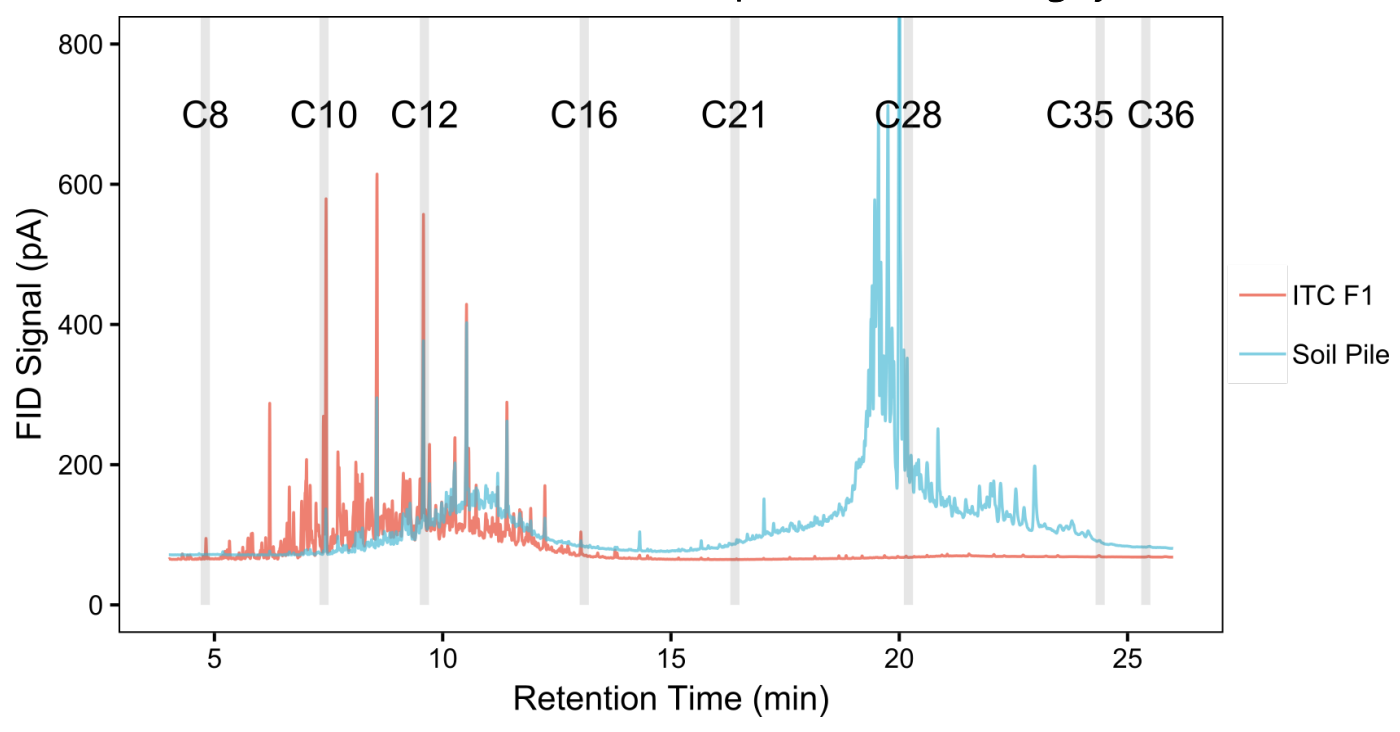

\subsection{Study optimization}

Classic Fenton's Reagent requires a sustained pH less than 3 to convert oxidized Fe(III) to Fe(II) and to drastically improve overall Fe solubility and availability. The $\mathrm{pH}$ measurements of 1:1 soil:water extracts shaken overnight were 7.86 and 9.37 for ITC F1 and Soil Pile, respectively. The geologic composition of the boulders, rock, and coarse-grained soils from the weathered volcanic bedrock is commonly alkaline (Affleck et al 2017; Balks et al. 2013), highlighting the need for $\mathrm{pH}$ modification for Fenton's Reagent treatment. Optimization samples were prepared identically to treatment samples to determine the quantity of added $\mathrm{H}_{2} \mathrm{SO}_{4}$ needed to achieve $\mathrm{pH}$ less than 3. Table 4 shows that adding $\mathrm{H}_{2} \mathrm{O}_{2}$ and iron sulfate alone led to a significant decrease in $\mathrm{pH}$ for both soil samples, but adding 90 to 210 $\mu \mathrm{L}$ of $1 \mathrm{M} \mathrm{H}_{2} \mathrm{SO}_{4}$ was needed to bring the $\mathrm{pH}$ below 3. After shaking for one day, the $\mathrm{pH}$ for both soils rose to between 4.6 and 4.9, depending on $\mathrm{H}_{2} \mathrm{O}_{2}$ concentration, and required additional $\mathrm{H}_{2} \mathrm{SO}_{4}$.

Table 4. Acid addition optimization results for Fenton's Reagent treatment.

\begin{tabular}{|l|c|c|c|c|c|}
\hline & \multirow{2}{*}{ Sample } & $\begin{array}{c}\mathrm{H}_{2} \mathrm{O}_{2} \\
(\%)\end{array}$ & $\mathrm{pH}$ & $\begin{array}{c}1 \mathrm{M} \mathrm{H}_{2} \mathrm{SO}_{4} \text { to } \mathrm{pH}<3 \\
(\mu \mathrm{L})\end{array}$ & \multicolumn{2}{|c|}{$\mathrm{t}=1$ Day with Shaking } \\
\hline ITC F1 & 3 & 3.8 & 90 & 4.58 & $\begin{array}{c}1 \mathrm{M} \mathrm{H}_{2} \mathrm{SO}_{4} \text { to } \mathrm{pH}<3 \\
(\mu \mathrm{L})\end{array}$ \\
\hline ITC F1 & 10 & 4.1 & 90 & 4.87 & 420 \\
\hline Soil Pile & 3 & 4.6 & 150 & 4.6 & 210 \\
\hline Soil Pile & 10 & 4.9 & 210 & 4.9 & 510 \\
\hline
\end{tabular}




\subsection{Study observations}

Immediately following addition of $\mathrm{H}_{2} \mathrm{O}_{2}$, some sample containers became warm to hot to the touch from exothermic reactions occurring. Bubbles of evolved gas occurred throughout the 21-day study and were also noted in the aqueous layer postextraction, potentially due to oxidation of the added hexane.

The experiments were conducted in cold rooms that were set to $4^{\circ} \mathrm{C}$ but subject to variability in temperature due to the operation state and personnel ingress and egress. A temperature logger placed adjacent to the shaker table recorded air temperature over the 21-day experiments for each soil. Temperature was relatively variable from the beginning of the ITC F1 experiment until 13 August when the experiment was moved to a different cold room, marked in (Figure 3 ) by a short-lived ( $<30$ minute) increase in temperature to $11^{\circ} \mathrm{C}$. Temperatures were slightly cooler and less variable in the new cold room for the rest of the ITC F1 and Soil Pile experiments (Figure 3). Overall the mean temperature was $4.72^{\circ} \mathrm{C}$, the median was $4.56^{\circ} \mathrm{C}$, and the standard deviation was $0.97^{\circ} \mathrm{C}$.

Figure 3. Air temperatures adjacent to the experiment's shaker table during the 21-day experiments. The dashed line represents the mean temperature.

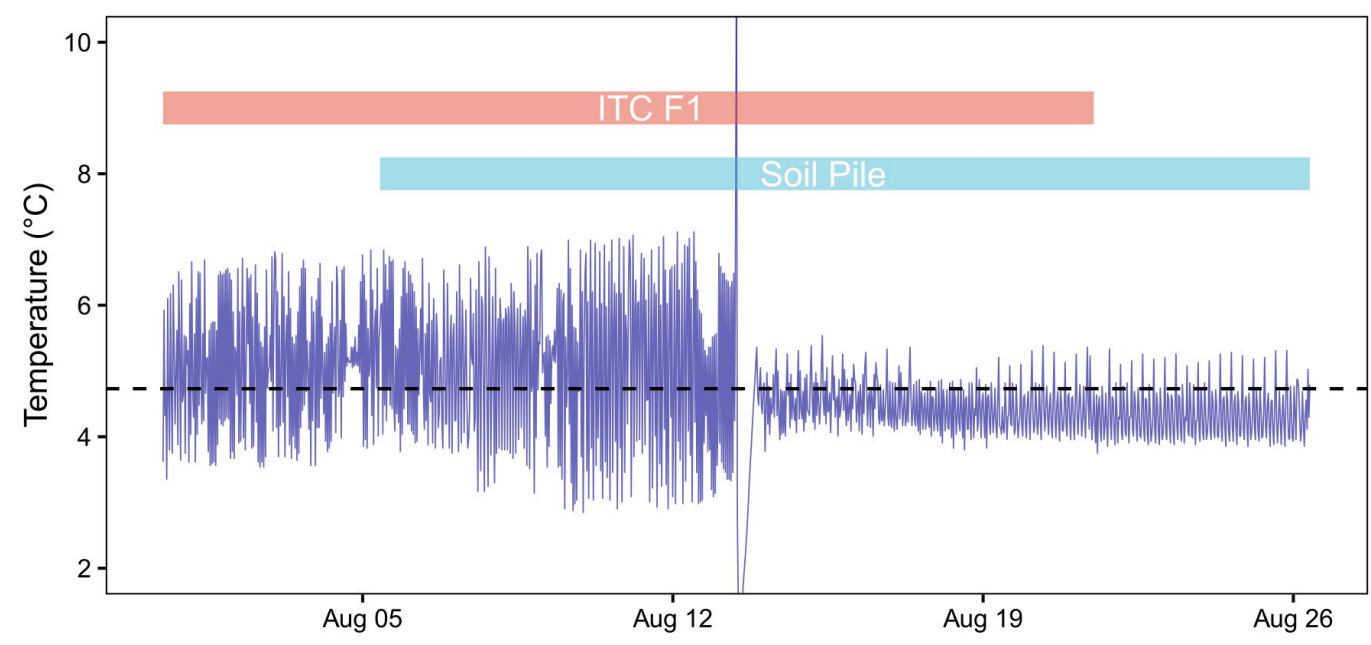

\subsection{Treatability results}

Figure 4 and Appendix A present the posttreatment TPH data for the ITC F1 and Soil Pile soils. Despite observations of oxidative reactions occurring in the soils, TPH concentrations remained generally within the range of the initial pretreatment concentration until 2 days for ITC F1 and for the 
entire 21 days for Soil Pile. Notable temporary out-of-trend increases and decreases in TPH are present in the time series for both soils and likely reflect subsampling variability that was not capture in the triplicate initial samples. We expected, based on the literature, effective treatment to induce a significant $(>50 \%)$ and time-consistent decrease in TPH concentration (Lu et al. 2010; Mater et al. 2007; Tsai and Kao 2009).

Figure 4. Posttreatment TPH concentrations in ITC F1 and Soil Pile samples by reaction time and treatment type. The dotted lines represent mean \pm 1 standard deviation bounds of pretreatment TPH concentrations.
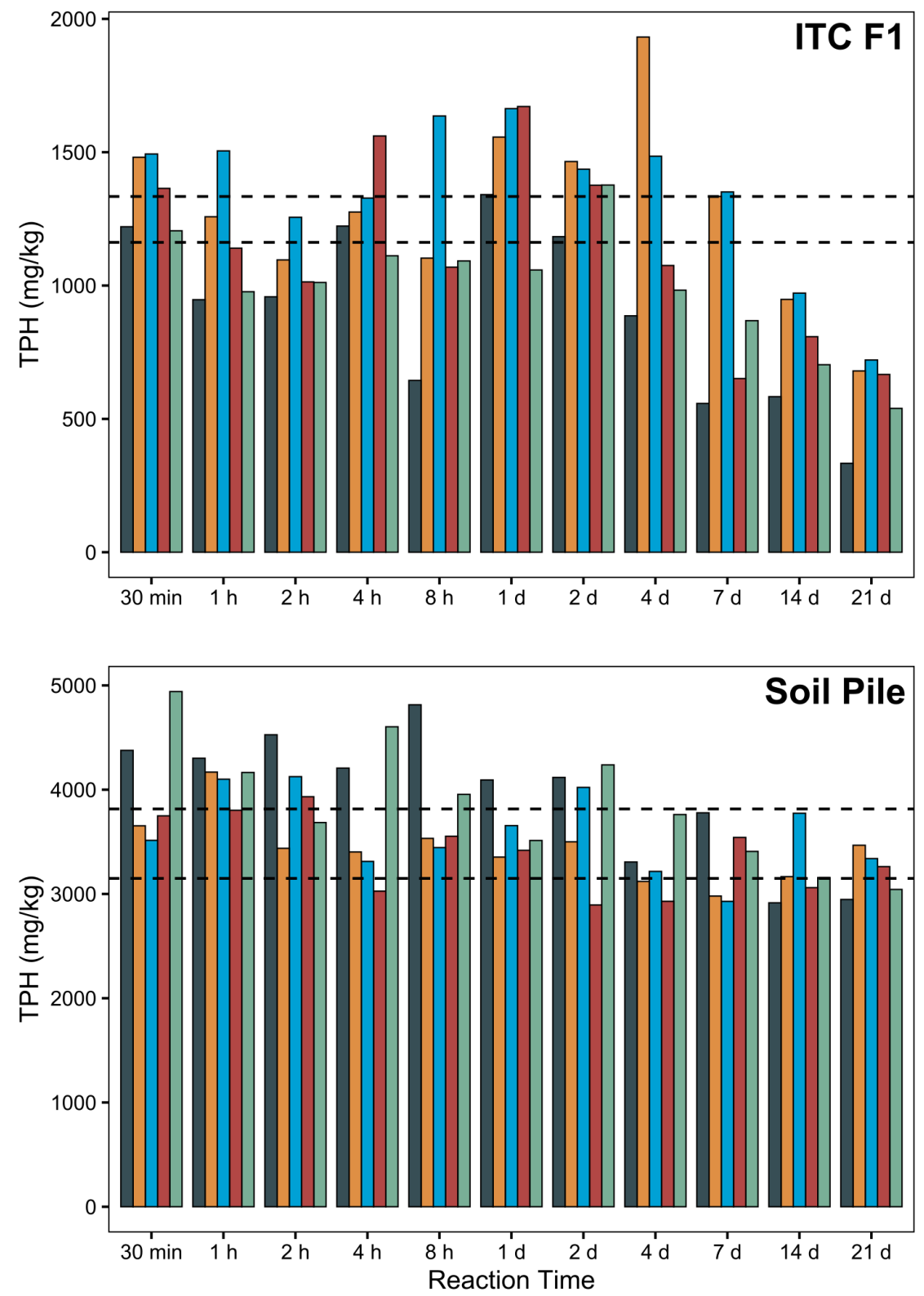
For ITC F1, TPH concentrations generally decreased between 4 days and 21 days to approximately half of the pretreatment concentration for all treatments. The MFR treatments at both $\mathrm{H}_{2} \mathrm{O}_{2}$ concentrations appeared to slightly outperform the FR treatments. However, the control consistently produced lower TPH concentrations than any of the treatments. This unexpected degradation in the control samples suggests relatively rapid bioor abiotic degradation. Experimental conditions were nonsterile, so colonization by local petroleum-degrading bacteria cannot be ruled out. Enhanced biodegradation in the control would suggest that $\mathrm{pH}$ or other environmental conditions in the treatments were relatively inhospitable. The low $\mathrm{pH}$ for the FR treatments may have inhibited biodegradation and explain its generally poor performance relative to the less acidic MFR treatments and circumneutral control. Despite the cool environmental conditions, loss to volatilization is also a possibility for this soil; however, we would expect this effect would to be the same across all treatments. Overall, these results indicate that chemical oxidation had a negligible effect on petroleum-compound concentrations relative to other processes.

For Soil Pile, TPH concentrations remained generally within the subsampling variability of initial TPH concentrations for all time steps and treatments, including the control. To investigate compositional changes that may be masked by the TPH metric, Figure 5 shows the HMW portion of the chromatograms. The HMW results broadly reflect the TPH results, with generally higher concentrations early in the study but no major changes throughout the 21-day study.

Kinetic limitations by the temperature used in the study were investigated by repeating the experiment at room temperature $\left(\sim 20^{\circ} \mathrm{C}\right)$ for a 4-day period. Adequate soil remained for only the Soil Pile samples. Table 5 compares the results of this room temperature study. Room temperature TPH concentrations after 4 days were not consistently lower than the original experiment at $4^{\circ} \mathrm{C}$ after 4 days, indicating temperature was not a limiting factor in chemical oxidation of this soil. 
Figure 5. Posttreatment HMW concentrations in Soil Pile samples by reaction time and treatment type. Dotted lines represent mean \pm 1 standard deviation bounds of pretreatment HMW concentrations.

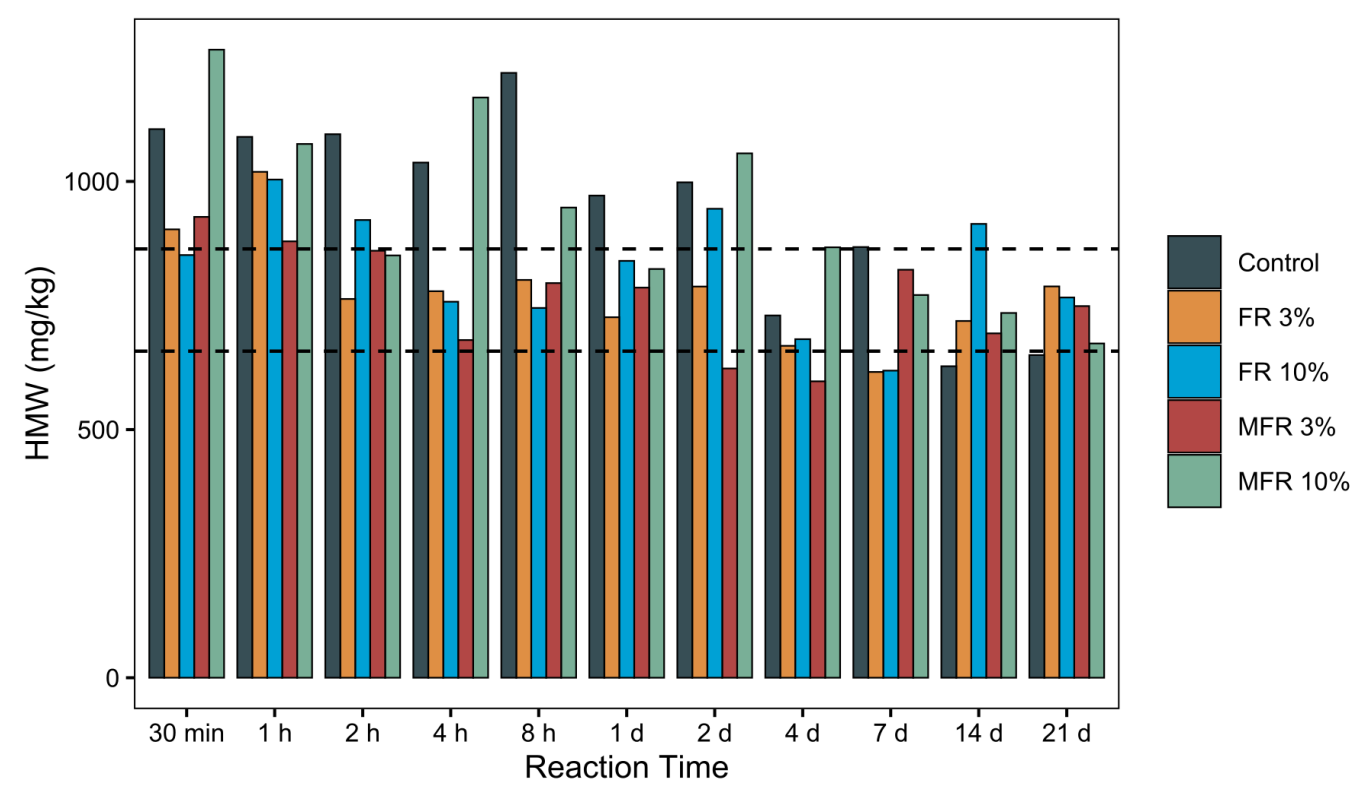

Table 5. Treatability results for Soil Pile at room temperature and $4^{\circ} \mathrm{C}$ over 4 days.

\begin{tabular}{|l|c|c|}
\hline \multirow{2}{*}{\multicolumn{1}{|c|}{ Treatment }} & \multicolumn{2}{|c|}{ TPH (HMW) Concentration $(\mathrm{mg} / \mathrm{kg})$} \\
\cline { 2 - 3 } & Room Temperature & $4^{\circ} \mathrm{C}$ \\
\hline FR 3\% & $2900(760)$ & $3120(670)$ \\
\hline FR 10\% & $3060(770)$ & $3220(680)$ \\
\hline MFR 3 \% & $3720(960)$ & $2930(600)$ \\
\hline MFR 10\% & $3300(824)$ & $3760(870)$ \\
\hline Control & $3930(1050)$ & $3300(730)$ \\
\hline
\end{tabular}

\subsection{Limitations and field-scale applicability}

The negligible chemical oxidation of petroleum hydrocarbons in this study is in contrast to those reported in many bench-scale experiments and some field-scale soil experiments (e.g., Watts 1992; Watts and Dilly 1996; Kong et al. 1998; Lu et al. 2010; Mater et al. 2007; Sherwood and Cassidy 2014; Tsai and Kao 2009). In our study, temperature was not a limiting factor for at least one of the McMurdo soils, leaving the soil composition or the treatment process as a potential explanatory variable in the observed insignificant degradation. For processing, we sieved the soils only to remove gravel-sized particles, whereas other bench-scale experiments mechanically homogenized soils to smaller particle sizes (e.g., Sherwood and 
Cassidy 2014; Tsai and Kao 2009; Mater et al. 2007). Homogenization increases the soil surface area and may promote the oxidative treatment to interact with contaminated soil. Field-scale homogenization is possible in an ex situ treatment but is energy intensive. We selected the strengths of $\mathrm{H}_{2} \mathrm{O}_{2}$ used in this treatability study for their relative safety in handling by field personnel; however, stronger $\mathrm{H}_{2} \mathrm{O}_{2}$ concentrations are available. A previous Fenton's Reagent study on the McMurdo soil pile used approximately $30 \% \mathrm{H}_{2} \mathrm{O}_{2}$ on homogenized soil at room temperature and observed significant reductions ( 97\%) in TPH (N.D. Williams, pers. comm., 2017). Kakarla et al. (2002) found in groundwater applications that $\mathrm{H}_{2} \mathrm{O}_{2}$ concentrations between $5 \%$ and $20 \%$ were more effective than higher concentrations, but the increased reactivity of soil surfaces may require a higher concentration or repeated dosing. Villa et al. (2010) found that sequential additions of $\mathrm{H}_{2} \mathrm{O}_{2}$ improved TPH degradation up to $80 \%$ in a diesel-contaminated soil. The molar oxidant-to-hydrocarbon ratios used in our treatability study varied between 25 and 94 and should have delivered excess $\mathrm{H}_{2} \mathrm{O}_{2}$ for complete oxidation of the samples. Competitive reactivity with soil minerals may have occurred and warrants further investigation. 


\section{Conclusions}

This treatability study found that Fenton's Reagent and Modified Fenton's Reagent with $\mathrm{H}_{2} \mathrm{O}_{2}$ concentrations of $3 \%$ and $10 \%$ applied to minimally processed McMurdo soils at $4^{\circ} \mathrm{C}$ had low to no effect on TPH concentrations over 3 weeks. This finding is in contrast to bench-scale studies that often use homogenized soil and stronger (30-50 wt\%) $\mathrm{H}_{2} \mathrm{O}_{2}$ concentrations but is consistent with an in situ field study at Old Casey Station, Antarctica (Ferguson et al. 2004). Ex situ oxidative treatment of soil at McMurdo Station is likely feasible with the addition of mechanical homogenization, relatively high $\mathrm{H}_{2} \mathrm{O}_{2}$ concentrations, and repeated $\mathrm{H}_{2} \mathrm{O}_{2}$ treatments. For effective chemical oxidation of McMurdo Station soil, further study is needed, primarily of oxidant type and concentration, number of treatments, mineral catalyst (if any), soil processing, and reaction agitation. Given the high cost of operation in Antarctica, such optimization should be compared on a cost-per-ton basis to off-site disposal. 


\section{Recommendations}

Based on the findings presented here and the results of prior studies in Antarctica, we recommend the following studies to assess the feasibility of remediating hydrocarbon-contaminated soils at McMurdo Station:

1. Optimization of peroxide chemical oxidation. There are a multitude of variable factors involved in peroxide-based treatment that may control remediation efficacy, including peroxide concentration, reagent-to-slurry ratio, catalyst type, catalyst-to-peroxide ratio, solution $\mathrm{pH}$, treatment volume, and frequency of application. Further practical aspects of soil processing (e.g., sieving and mechanical homogenization) and reagent mixing should also be considered. For example, In-Situ Oxidative Technologies, Inc. offers a commercial modified Fenton's Reagent technology for petroleum compounds.

2. Alternative chemical oxidants. Other oxidative treatments may more effectively degrade hydrocarbons at McMurdo Station. Oxidants such as permanganate, persulfate, percarbonate, and ozone have been demonstrated for various organic contaminants (Siegrist 2010). For example, Regenesis, Inc., offers two oxidative products based on percarbonate and persulfate that it markets for treatment of petroleum hydrocarbons.

3. Biopiles. Excavation of contaminated soils, amendment with fertilizers, construction of piles, and periodic mechanical turning can accelerate the natural biodegradation of organic contaminants. McWatters et al. (2016) used biopiles to treat $590 \mathrm{~m}^{3}$ of diesel-contaminated soil at Casey Station, Antarctica, reducing TPH concentrations from $3500 \mathrm{mg} / \mathrm{kg}$ to $900 \mathrm{mg} / \mathrm{kg}$ over 5 years.

Prior to further studies, we recommend identifying fundamental constraints on any remediation technology:

1. Cleanup volumes and target levels. The volume of soil and concentration level to which contaminants must be reduced are major controls on the logistics and overall success of remediation efforts. If a technology cannot achieve target concentration levels, then it may be no more beneficial than off-site disposal. Further, the volume and cleanup level dictate the amount of reagents (oxidants and catalysts for chemical oxidation and fertilizers 
for biopiles) needed for remediation and their overall external effects on environmental quality (e.g., nutrient runoff, soil pH, and soil structure).

2. Ex situ versus in situ treatments. In situ treatment of contaminated soil is often desirable but less effective than ex situ treatment. Ex situ treatment generally ensures that the treatment has complete and frequent interaction with the contaminants. The preremediation decision on ex situ versus in situ treatment will inform feasibility studies and expectations for treatable soil volumes and target contaminant levels.

3. Energy and materiel requirements for processing. Ex situ treatments require processing steps such as sieving, particle size reduction, and mechanical agitation that are both energy intensive and use specialized equipment. The availability of equipment and personnel to initiate and maintain treatments must be considered.

4. Treatment byproducts and effects. Most treatments involve relatively innocuous chemicals, such as peroxide, which degrades contaminants to water and carbon dioxide; but classical Fenton's Reagent requires soil acidification with strong acid. Highly fertilized biopiles may leach excess nutrients into waterbodies. Some of the oxidative treatments have strongly exothermic reactions that could heat surrounding soil during in situ treatments and affect soil structure, particularly permafrost. Removal of contaminated soil during ex situ treatments may affect soil structure, especially on permafrost where the active layer in adjacent soils may be affected.

Identifying an effective treatment, or suite of treatments, for hydrocarbons at McMurdo Station could significantly save costs compared with off-continent disposal. However, prior to large-scale implementation, further study is needed to identify such treatments to evaluate their potential overall impacts. 


\section{References}

Affleck, R. T., S. Campbell, S. Sinclair, and B. Tischbein. 2017. Subsurface Assessment at McMurdo Station, Antarctica. ERDC/CRREL TR-17-4. Hanover, NH: U.S. Army Engineer Research and Development Center.

Affleck, R. T., M. Carr, L. Elliot, C. Chan, and M. Knuth. 2014. Pollutant Concentration in Runoff at McMurdo Station, Antarctica. ERDC/CRREL TR-14-15. Hanover, NH: U.S. Army Engineer Research and Development Center.

- 2012. Drainage Assessment and Flow Monitoring at McMurdo Station during Austral Summer. ERDC/CRREL TR-12-3. Hanover, NH: U.S. Army Engineer Research and Development Center.

Aislabie, J. M., M. R. Balks, J. M. Foght, and E. J. Waterhouse. 2004. "Hydrocarbon Spills on Antarctic Soils: Effects and Management." Environmental Science and Technology 38 (5): 1265-1274. https://doi.org/10.1021/es0305149.

Balks, M. R., J. López-Martínez, S. V. Goryachkin, N. S. Mergelov, C. E. G. R. Schaefer, F. N. B. Simas, P. C. Almond, G. G. C. Claridge, M. McLeod, and J. Scarrow. 2013. "Windows on Antarctic Soil-Landscape Relationships: Comparison across Selected Regions on Antarctica." In Antarctic Palaeoenvironments and EarthSurface Processes, ed. M. J. Hambrey, P. F. Barker, P. J. Barrett, V. Bowman, B. Davies, J. L. Smellie, and M. Tranter, 381:397-410. Special Publication. London: Geological Society. http://dx.doi.org/10.1144/SP381.9.

Campbell, S., R. T. Affleck, and S. Sinclair. 2018. "Ground-Penetrating Radar Studies of Permafrost, Periglacial, and Near-Surface Geology at McMurdo Station, Antarctica." Cold Regions Science and Technology 148:38-49. https://doi.org/10.1016/i.coldregions.2017.12.008.

Eriksson, M., J.-O. Ka, and W. W. Mohn. 2001. "Effects of Low Temperature and FreeThaw Cycles on Hydrocarbon Biodegradation in Arctic Tundra Soil." Applied and Environmental Microbiology 67 (11): 5107-5112. https://doi.org/10.1128 LAEM.67.11.5107-5112.2001.

Fenwick, J., and D. Winkler. 2016. Geotechnical Assessment Report: McMurdo Station, Ross Island, Antarctica. Report Number 1535646-7407-002-R. Christchurch, New Zealand: Golder Associates.

Fenwick, J., D. Winkler, and B. Neahusan. 2017. Geotechnical Assessment Report: McMurdo Station, Ross Island, Antarctica-Phase II. Report Number 15356467407-007-R. Christchurch, New Zealand: Golder Associates.

Ferguson, S. H., P. D. Franzmann, A. T. Revill, I. Snape, and J. L. Rayner. 2003. "The Effects of Nitrogen and Water on Mineralization of Hydrocarbons in DieselContaminated Terrestrial Antarctic Soils." Cold Regions Science and Technology 37 (2): 197-212. https://doi.org/10.1016/S0165-232X(03)00041-7. 
Ferguson, S. H., A. Z. Woinarski, I. Snape, C. E. Morris, and A. T. Revill. 2004. "A Field Trial of In Situ Chemical Oxidation to Remediate Long-Term Diesel Contaminated Antarctic Soil.” Cold Regions Science and Technology 40 (1-2): 47-6o. https://doi.org/10.1016/j.coldregions.2004.05.008.

Foley, W. T., and P. A. Giguère. 1951. "Hydrogen Peroxide and Its Analogues. II. Phase Equilibrium in the System Hydrogen Peroxide - Water." Canadian Journal of Chemistry 29 (2): 123-132.

Haehnel, R. B., T. Melendy, and G. L. Blaisdell. 2017. Feasibility of Using Alternate Fuels in the U.S. Antarctic Program. ERDC/CRREL TR-17-15. Hanover, NH: U.S. Army Engineer Research and Development Center.

Interstate Technology and Regulatory Council. 2005. Technical and Regulatory Guidance for In Situ Chemical Oxidation of Contaminated Soil and Groundwater. 2nd ed. Washington, DC: Interstate Technology \& Regulatory Council, In Situ Chemical Oxidation Team. https://itrcweb.org/GuidanceDocuments /ISCO-2.pdf.

Kakarla, P. K., T. Andrews, R. S. Greenberg, and D.S. Zervas. 2002. “Modified Fenton's Processes for Effective In-Situ Chemical Oxidation-Laboratory and Field Evaluation." Remediation 12 (4): 23-36. https://doi.org/10.1002/rem.10043.

Klein, A. G., S. T. Sweet, T. L. Wade, J. L. Sericano, and M.C. Kennicutt. 2012. "Spatial Patterns of Total Petroleum Hydrocarbons in the Terrestrial Environment at McMurdo Station, Antarctica.” Antarctic Science 24 (5): 450-466. https://doi.org/10.1017/S0954102012000429.

Klein, A. G., M. C. Kennicutt, G. A. Wolff, S. T. Sweet, T. Bloxom, D. A. Gielstra, and M. Cleckley. 2008. "The Historical Development of McMurdo Station, Antarctica, an Environmental Perspective.” Polar Geography 31 (3-4): 119-144. https://doi.org/10.1080/10889370802579856.

Kong, S.-H., R. J. Watts, and J.-H. Choi. 1998. "Treatment of Petroleum-Contaminated Soils Using Iron Mineral Catalyzed Hydrogen Peroxide." Chemosphere 37 (8): 1473-1482. https://doi.org/10.1016/S0045-6535(98)00137-4.

Lu, M., Z. Zhang, W. Qiao, Y. Guan, M. Xiao, and C. Peng. 2010. "Removal of Residual Contaminants in Petroleum-Contaminated Soil by Fenton-like Oxidation." Journal of Hazardous Materials 179 (1-3): 604-611. https://doi.org/10.1016 ¿i.jhazmat.2010.03.046.

Mater, L., E. V. C. Rosa, J. Berto, A. X. R. Corrêa, P. R. Schwingel, and C. M. Radetski. 2007. "A Simple Methodology to Evaluate Influence of $\mathrm{H}_{2} \mathrm{O}_{2}$ and $\mathrm{Fe}^{2+}$ Concentrations on the Mineralization and Biodegradability of Organic Compounds in Water and Soil Contaminated with Crude Petroleum." Journal of Hazardous Materials 149 (2): 379-386. https://doi.org/10.1016/i.jhazmat.2007.04.005.

McWatters, R. S., D. Wilkins, T. Spedding, G. Hince, B. Raymond, G. Lagerewskij, D. Terry, L. Wise, and I. Snape. 2016. "On Site Remediation of a Fuel Spill and Soil Reuse in Antarctica." Science of the Total Environment 571:963-973. https://doi.org/10.1016/i.scitotenv.2016.07.084. 
NSF (National Science Foundation). 2019. Final Comprehensive Environmental Evaluation for Continuation and Modernization of McMurdo Station Area Activities. Alexandria, VA: National Science Foundation. https://www.nsf.gov/geo/opp Lantarct/treaty/cees/AIMS/Final\%20CEE_McMurdo\%20Modernization_v8_05Aug2019.pdf.

Sherwood, M. K., and D. P. Cassidy. 2014. "Modified Fenton Oxidation of Diesel Fuel in Arctic Soils Rich in Organic Matter and Iron." Chemosphere 113:56-61. https://doi.org/10.1016/i.chemosphere.2014.04.048.

Siegrist, R. 2010. "Attachment 17, Laboratory Bench Testing for Contaminant Treatability and Byproducts." In In Situ Chemical Oxidation for Groundwater Remediation: Site Specific Engineering and Technology Application, Technology Practices Manual. Alexandria, VA: Strategic Environmental Research and Development Program. https://www.serdp-estcp.org/Program-Areas/EnvironmentalRestoration/Contaminated-Groundwater/Persistent-Contamination/ER-200623.

Tsai, T. T., and C. M. Kao. 2009. "Treatment of Petroleum-Hydrocarbon Contaminated Soils Using Hydrogen Peroxide Oxidation Catalyzed by Waste Basic Oxygen Furnace Slag.” Journal of Hazardous Materials 170 (1): 466-472. https://doi.org/10.1016/i.jhazmat.2009.04.073.

Villa, R. D., A. G. Trovo, and R. F. Pupo Nogueira. 2010. "Diesel Degradation in Soil Fenton Process.” Journal of the Brazilian Chemical Society 21 (6): 1088-1095. https://dx.doi.org/10.1590/S0103-50532010000600019.

Watts, R. J. 1992. "Hydrogen Peroxide for Physicochemically Degrading PetroleumContaminated Soils." Remediation 2 (4): 413-425. https://doi.org/10.1002/rem.3440020407.

Watts, R. J., and S. E. Dilly. 1996. "Evaluation of Iron Catalysts for the Fenton-like Remediation of Diesel-Contaminated Soil." Journal of Hazardous Materials 51 (1-3): 209-224. 


\section{Appendix A: Supporting Figures and Data}

Figure A-1. GC-FID chromatograms of soil samples and the hydrocarbon standards for diesel $(5000 \mathrm{mg} / \mathrm{L})$, gasoline $(500 \mathrm{mg} / \mathrm{L}), \mathrm{JP}-5$ (5000 mg/L), JP-8 $(5000 \mathrm{mg} / \mathrm{L})$, and hydraulic oil $(500 \mathrm{mg} / \mathrm{L})$. The gasoline standard signal is $5 \times$ for plotting.
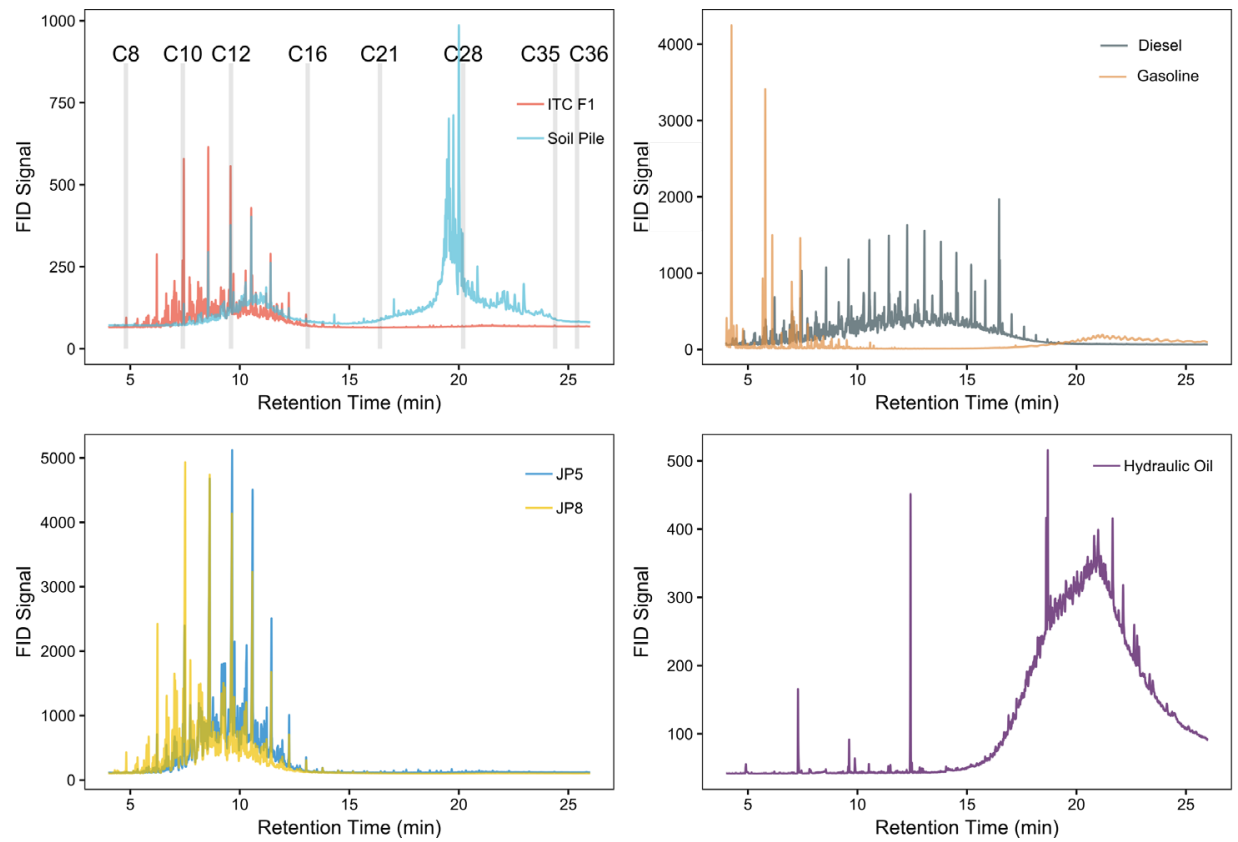

Figure A-2. Posttreatment TPH concentrations in ITC F1 samples by reaction time and treatment type. Dotted lines represent mean \pm 1 standard deviation bounds of pretreatment TPH concentrations.
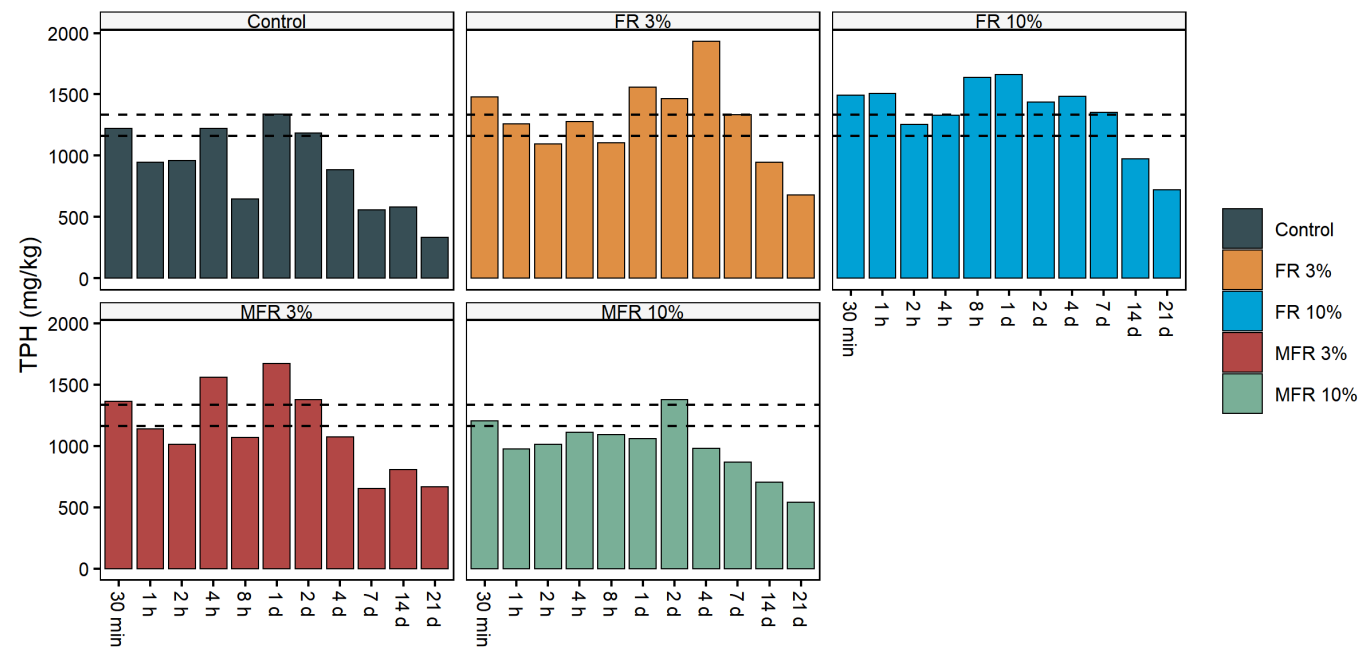

Reaction Time 
Figure A-3. Posttreatment TPH concentrations in Soil Pile samples by reaction time and treatment type. Dotted lines represent mean \pm 1 standard deviation bounds of pretreatment $\mathrm{TPH}$ concentrations.

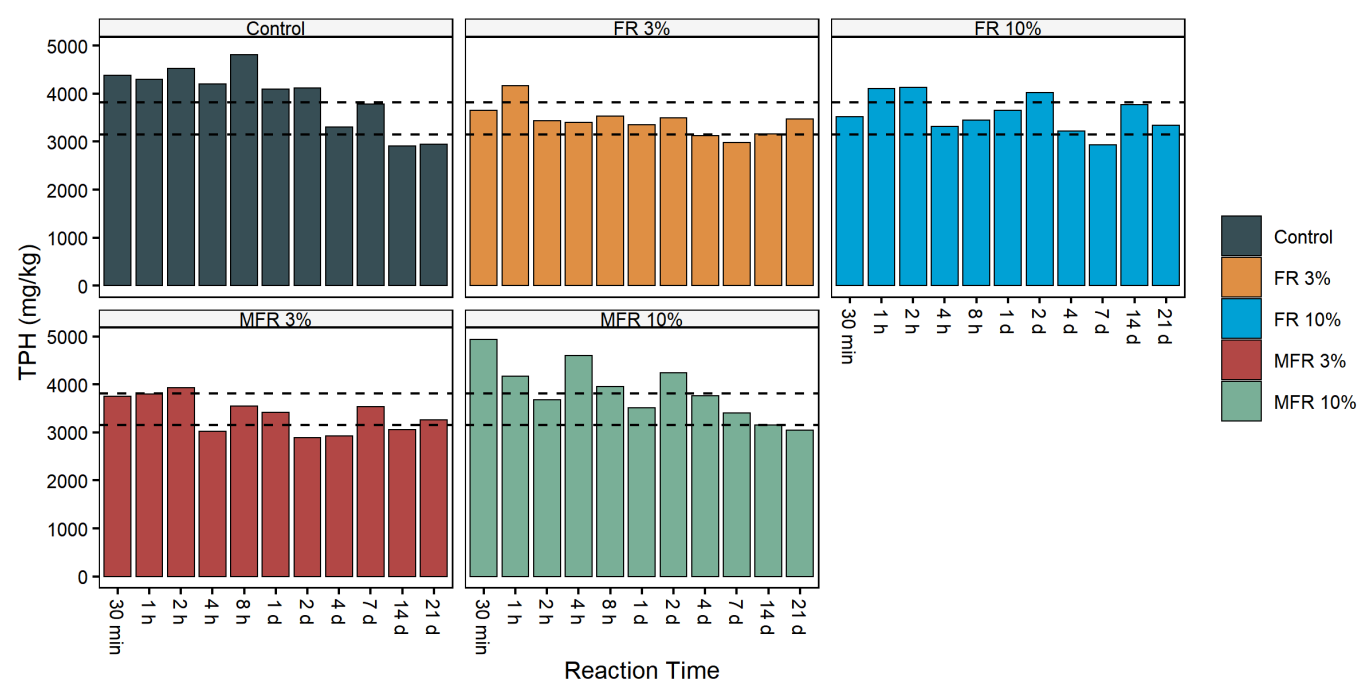

Figure A-4. Posttreatment HMW concentrations in Soil Pile samples by reaction time and treatment type. Dotted lines represent mean \pm 1 standard deviation bounds of pretreatment HMW concentrations.

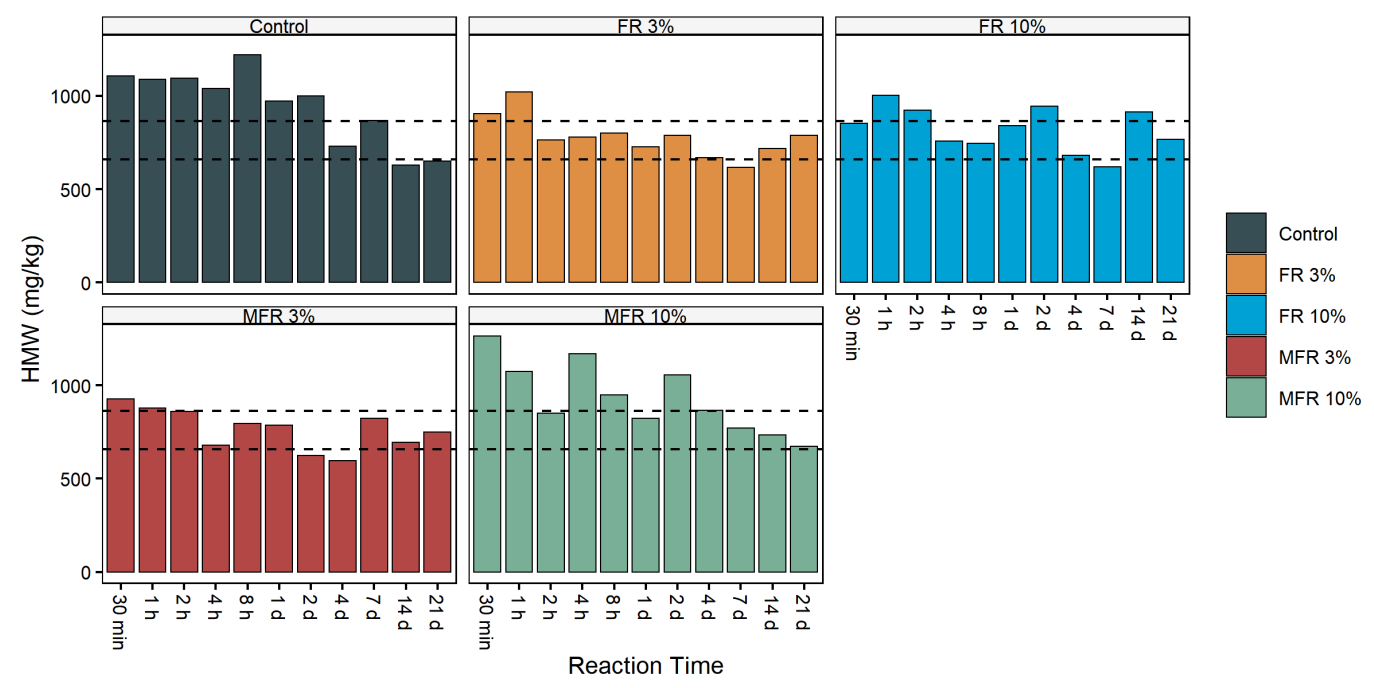


Table A-1. Experimental data for ITC F1.

\begin{tabular}{|c|c|c|c|}
\hline ID & Treatment & Time & $\mathrm{TPH}(\mathrm{mg} / \mathrm{kg})$ \\
\hline ITC F1 R1 & None & 0 & 1265 \\
\hline ITC F1 R2 & None & 0 & 1325 \\
\hline ITC F1 R3 & None & 0 & 1155 \\
\hline ITC F1 A 30 min & FR 3\% & $30 \mathrm{~min}$ & 1481 \\
\hline ITC F1 A 1 hr & FR 3\% & $1 \mathrm{hr}$ & 1258 \\
\hline ITC F1 A 2 hr & FR 3\% & $2 \mathrm{hr}$ & 1096 \\
\hline ITC F1 A 4 hr & FR 3\% & $4 \mathrm{hr}$ & 1276 \\
\hline ITC F1 A 8 hr & FR 3\% & $8 \mathrm{hr}$ & 1103 \\
\hline ITC F1 A 1 day & FR 3\% & 1 day & 1557 \\
\hline ITC F1 A 2 days & FR 3\% & 2 days & 1465 \\
\hline ITC F1 A 4 days & FR 3\% & 4 days & 1932 \\
\hline ITC F1 A 7 days & FR 3\% & 7 days & 1334 \\
\hline ITC F1 A 14 days & FR 3\% & 14 days & 948 \\
\hline ITC F1 A 21 days & FR 3\% & 21 days & 680 \\
\hline ITC F1 B $30 \mathrm{~min}$ & FR 10\% & $30 \mathrm{~min}$ & 1493 \\
\hline ITC F1 B 1 hr & FR 10\% & $1 \mathrm{hr}$ & 1505 \\
\hline ITC F1 B 2 hr & FR 10\% & $2 \mathrm{hr}$ & 1256 \\
\hline ITC F1 B 4 hr & FR $10 \%$ & $4 \mathrm{hr}$ & 1328 \\
\hline ITC F1 B 8 hr & FR 10\% & $8 \mathrm{hr}$ & 1636 \\
\hline ITC F1 B 1 day & FR 10\% & 1 day & 1663 \\
\hline ITC F1 B 2 days & FR 10\% & 2 days & 1436 \\
\hline ITC F1 B 4 days & FR $10 \%$ & 4 days & 1485 \\
\hline ITC F1 B 7 days & FR 10\% & 7 days & 1351 \\
\hline ITC F1 B 14 days & FR 10\% & 14 days & 972 \\
\hline ITC F1 B 21 days & FR 10\% & 21 days & 721 \\
\hline ITC F1 C $30 \mathrm{~min}$ & MFR 3\% & $30 \mathrm{~min}$ & 1364 \\
\hline ITC F1 C $1 \mathrm{hr}$ & MFR 3\% & $1 \mathrm{hr}$ & 1140 \\
\hline ITC F1 C 2 hr & MFR 3\% & $2 \mathrm{hr}$ & 1014 \\
\hline ITC F1 C 4 hr & MFR 3\% & $4 \mathrm{hr}$ & 1561 \\
\hline ITC F1 C 8 hr & MFR 3\% & $8 \mathrm{hr}$ & 1069 \\
\hline ITC F1 C 1 day & MFR 3\% & 1 day & 1671 \\
\hline ITC F1 C 2 days & MFR 3\% & 2 days & 1376 \\
\hline ITC F1 C 4 days & MFR 3\% & 4 days & 1075 \\
\hline ITC F1 C 7 days & MFR 3\% & 7 days & 651 \\
\hline ITC F1 C 14 days & MFR 3\% & 14 days & 808 \\
\hline ITC F1 C 21 days & MFR 3\% & 21 days & 667 \\
\hline ITC F1 D $30 \mathrm{~min}$ & MFR 10\% & $30 \mathrm{~min}$ & 1205 \\
\hline ITC F1 D 1 hr & MFR $10 \%$ & $1 \mathrm{hr}$ & 977 \\
\hline ITC F1 D 2 hr & MFR $10 \%$ & $2 \mathrm{hr}$ & 1011 \\
\hline ITC F1 D 4 hr & MFR 10\% & $4 \mathrm{hr}$ & 1112 \\
\hline
\end{tabular}




\begin{tabular}{|c|c|c|c|}
\hline ID & Treatment & Time & TPH (mg/kg) \\
\hline ITC F1 D 8 hr & MFR $10 \%$ & $8 \mathrm{hr}$ & 1092 \\
\hline ITC F1 D 1 day & MFR 10\% & 1 day & 1058 \\
\hline ITC F1 D 2 days & MFR 10\% & 2 days & 1377 \\
\hline ITC F1 D 4 days & MFR $10 \%$ & 4 days & 983 \\
\hline ITC F1 D 7 days & MFR $10 \%$ & 7 days & 868 \\
\hline ITC F1 D 14 days & MFR 10\% & 14 days & 703 \\
\hline ITC F1 D 21 days & MFR 10\% & 21 days & 539 \\
\hline ITC F1 E $30 \mathrm{~min}$ & Control & $30 \mathrm{~min}$ & 1220 \\
\hline ITC F1 E 1 hr & Control & $1 \mathrm{hr}$ & 947 \\
\hline ITC F1 E 2 hr & Control & $2 \mathrm{hr}$ & 958 \\
\hline ITC F1 E 4 hr & Control & $4 \mathrm{hr}$ & 1223 \\
\hline ITC F1 E 8 hr & Control & $8 \mathrm{hr}$ & 644 \\
\hline ITC F1 E 1 day & Control & 1 day & 1341 \\
\hline ITC F1 E 2 days & Control & 2 days & 1183 \\
\hline ITC F1 E 4 days & Control & 4 days & 887 \\
\hline ITC F1 E 7 days & Control & 7 days & 558 \\
\hline ITC F1 E 14 days & Control & 14 days & 583 \\
\hline ITC F1 E 21 days & Control & 21 days & 333 \\
\hline
\end{tabular}

Table A-2. Experimental data for Soil Pile.

\begin{tabular}{|l|c|c|c|c|}
\hline & & \multirow{2}{*}{ ID } & & \multicolumn{2}{c|}{ Concentration (mg/kg) } \\
\cline { 4 - 5 } & Treatment & Time & TPH & HMW \\
\hline Soil Pile R1 & None & 0 & 3833 & 868 \\
\hline Soil Pile R2 & None & 0 & 3170 & 663 \\
\hline Soil Pile R3 & None & 0 & 3444 & 752 \\
\hline Soil Pile A 30 min & FR 3\% & $30 \mathrm{~min}$ & 3654 & 903 \\
\hline Soil Pile A 1 hr & FR 3\% & $1 \mathrm{hr}$ & 4168 & 1019 \\
\hline Soil Pile A 2 hr & FR 3\% & $2 \mathrm{hr}$ & 3438 & 763 \\
\hline Soil Pile A 4 hr & FR 3\% & $4 \mathrm{hr}$ & 3403 & 779 \\
\hline Soil Pile A 8 hr & FR 3\% & $8 \mathrm{hr}$ & 3533 & 801 \\
\hline Soil Pile A 1 day & FR 3\% & $1 \mathrm{~s}$ & 3354 & 726 \\
\hline Soil Pile A 2 days & FR 3\% & 2 days & 3500 & 788 \\
\hline Soil Pile A 4 days & FR 3\% & 4 days & 3120 & 669 \\
\hline Soil Pile A 7 days & FR 3\% & 7 days & 2980 & 616 \\
\hline Soil Pile A 14 days & FR 3\% & 14 days & 3166 & 719 \\
\hline Soil Pile A 21 days & FR 3\% & 21 days & 3467 & 788 \\
\hline Soil Pile B 30 min & FR 10\% & $30 \mathrm{~min}$ & 3514 & 852 \\
\hline Soil Pile B 1 hr & FR 10\% & $1 \mathrm{hr}$ & 4100 & 1004 \\
\hline Soil Pile B 2 hr & FR 10\% & $2 \mathrm{hr}$ & 4125 & 922 \\
\hline Soil Pile B 4 hr & FR 10\% & $4 \mathrm{hr}$ & 3312 & 758 \\
\hline Soil Pile B 8 hr & FR 10\% & $8 \mathrm{hr}$ & 3444 & 745 \\
\hline
\end{tabular}




\begin{tabular}{|c|c|c|c|c|}
\hline \multirow[b]{2}{*}{ ID } & \multirow[b]{2}{*}{ Treatment } & \multirow[b]{2}{*}{ Time } & \multicolumn{2}{|c|}{ Concentration $(\mathrm{mg} / \mathrm{kg})$} \\
\hline & & & TPH & HMW \\
\hline Soil Pile B 1 day & FR $10 \%$ & 1 day & 3655 & 840 \\
\hline Soil Pile B 2 days & FR $10 \%$ & 2 days & 4022 & 945 \\
\hline Soil Pile B 4 days & FR 10\% & 4 days & 3216 & 682 \\
\hline Soil Pile B 7 days & FR $10 \%$ & 7 days & 2929 & 619 \\
\hline Soil Pile B 14 days & FR $10 \%$ & 14 days & 3774 & 914 \\
\hline Soil Pile B 21 days & FR 10\% & 21 days & 3339 & 766 \\
\hline Soil Pile C 30 min & MFR 3\% & $30 \mathrm{~min}$ & 3749 & 928 \\
\hline Soil Pile C $1 \mathrm{hr}$ & MFR 3\% & $1 \mathrm{hr}$ & 3802 & 879 \\
\hline Soil Pile C 2 hr & MFR 3\% & $2 \mathrm{hr}$ & 3933 & 860 \\
\hline Soil Pile C 4 hr & MFR 3\% & $4 \mathrm{hr}$ & 3027 & 680 \\
\hline Soil Pile C $8 \mathrm{hr}$ & MFR 3\% & $8 \mathrm{hr}$ & 3553 & 795 \\
\hline Soil Pile C 1 day & MFR 3\% & 1 day & 3418 & 786 \\
\hline Soil Pile $C 2$ days & MFR 3\% & 2 days & 2894 & 623 \\
\hline Soil Pile C 4 days & MFR 3\% & 4 days & 2929 & 597 \\
\hline Soil Pile C 7 days & MFR 3\% & 7 days & 3542 & 822 \\
\hline Soil Pile C 14 days & MFR 3\% & 14 days & 3060 & 694 \\
\hline Soil Pile C 21 days & MFR 3\% & 21 days & 3262 & 749 \\
\hline Soil Pile D $30 \mathrm{~min}$ & MFR $10 \%$ & $30 \mathrm{~min}$ & 4941 & 1265 \\
\hline Soil Pile D $1 \mathrm{hr}$ & MFR $10 \%$ & $1 \mathrm{hr}$ & 4165 & 1075 \\
\hline Soil Pile D 2 hr & MFR $10 \%$ & $2 \mathrm{hr}$ & 3685 & 851 \\
\hline Soil Pile D 4 hr & MFR $10 \%$ & $4 \mathrm{hr}$ & 4603 & 1169 \\
\hline Soil Pile D $8 \mathrm{hr}$ & MFR $10 \%$ & $8 \mathrm{hr}$ & 3955 & 947 \\
\hline Soil Pile D 1 day & MFR $10 \%$ & 1 day & 3513 & 824 \\
\hline Soil Pile D 2 days & MFR $10 \%$ & 2 days & 4238 & 1056 \\
\hline Soil Pile D 4 days & MFR $10 \%$ & 4 days & 3761 & 867 \\
\hline Soil Pile D 7 days & MFR 10\% & 7 days & 3408 & 771 \\
\hline Soil Pile D 14 days & MFR 10\% & 14 days & 3157 & 735 \\
\hline Soil Pile D 21 days & MFR 10\% & 21 days & 3043 & 673 \\
\hline Soil Pile E 30 min & Control & $30 \mathrm{~min}$ & 4377 & 1105 \\
\hline Soil Pile E $1 \mathrm{hr}$ & Control & $1 \mathrm{hr}$ & 4301 & 1090 \\
\hline Soil Pile E 2 hr & Control & $2 \mathrm{hr}$ & 4527 & 1095 \\
\hline Soil Pile E $4 \mathrm{hr}$ & Control & $4 \mathrm{hr}$ & 4207 & 1038 \\
\hline Soil Pile E $8 \mathrm{hr}$ & Control & $8 \mathrm{hr}$ & 4814 & 1219 \\
\hline Soil Pile E 1 day & Control & 1 day & 4093 & 971 \\
\hline Soil Pile E 2 days & Control & 2 days & 4118 & 998 \\
\hline Soil Pile E 4 days & Control & 4 days & 3306 & 730 \\
\hline Soil Pile E 7 days & Control & 7 days & 3778 & 868 \\
\hline Soil Pile E 14 days & Control & 14 days & 2915 & 628 \\
\hline Soil Pile E 21 days & Control & 21 days & 2947 & 650 \\
\hline
\end{tabular}




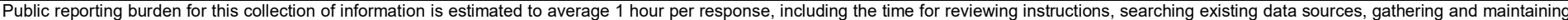

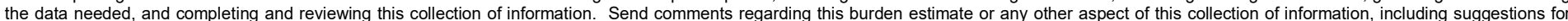

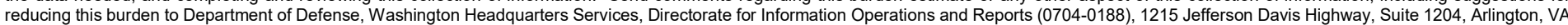

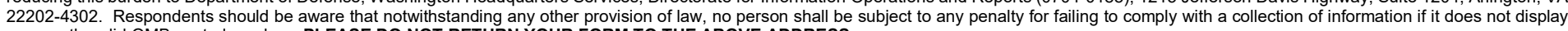
a currently valid OMB control number. PLEASE DO NOT RETURN YOUR FORM TO THE ABOVE ADDRESS.
1. REPORT DATE (DD-MM-YYYY) May 2020

\section{TITLE AND SUBTITLE}

Fenton's Reagent Treatability Study for Hydrocarbon-Contaminated Soils, McMurdo Station, Antarctica

\section{DATES COVERED (From - To)}

\section{5a. CONTRACT NUMBER}

5b. GRANT NUMBER

5c. PROGRAM ELEMENT NUMBER

5d. PROJECT NUMBER

5e. TASK NUMBER

5f. WORK UNIT NUMBER

8. PERFORMING ORGANIZATION REPORT NUMBER

ERDC/CRREL TR-20-5

U.S. Army Engineer Research and Development Center Cold Regions Research and Engineering Laboratory

72 Lyme Road

Hanover, NH 03755-1290
Antarctic Support Contract

Leidos

11951 Freedom Drive

Reston, VA 20190-5640

\section{SPONSORING / MONITORING AGENCY NAME(S) AND ADDRESS(ES)}

National Science Foundation

Office of Polar Programs

Antarctic Infrastructure and Logistics

2415 Eisenhower Avenue

Alexandria, VA 22314

12. DISTRIBUTION / AVAILABILITY STATEMENT

Approved for public release; distribution is unlimited.

\section{SUPPLEMENTARY NOTES}

Engineering for Polar Operations, Logistics, and Research (EPOLAR) EP-ANT-18-80, “Hydrogen Peroxide / Fenton's Reagent Treatability Study of McMurdo Station Hydrocarbon-Contaminated Soil”

\section{ABSTRACT}

Hydrocarbon-contaminated soil is distributed heterogeneously at McMurdo Station, Antarctica, which has served for over 60 years as the logistics hub for the U.S. Antarctic Program. Here we investigated the treatability of McMurdo Station's contaminated soil with chemical oxidation. Our study collected five soil samples in 2018 and 2019, of which two contained high levels ( $>100 \mathrm{mg} / \mathrm{kg}$ ) of total petroleum hydrocarbons (TPH) suitable for the treatability study. One soil (ITC) was characterized by $1250 \mathrm{mg} / \mathrm{kg}$ of predominantly midrange (n-C8 to n-C16) hydrocarbons, and the other (Soil Pile) was characterized by $3500 \mathrm{mg} / \mathrm{kg}$ of predominantly heavy molecular weight $(>\mathrm{n}-\mathrm{C} 21)$ hydrocarbons. We investigated the treatability of these soils with both Fenton's Reagent $(\mathrm{pH}<3$ with Fe2+) and modified Fenton's Reagent (chelated Fe2+), each with hydrogen peroxide concentrations of $3 \%$ and $10 \%$. Soil slurries were placed on a shaker table at $100 \mathrm{rpm}$ and $4{ }^{\circ} \mathrm{C}$ for up to 21 days. TPH concentrations were reduced by approximately $50 \%$ for ITC; however, the oxidative treatments did not out-perform controls. All treatments and controls yielded no significant reduction in Soil Pile TPH. Poor performance by these chemical oxidation treatments indicates that remediation of hydrocarbons at these sites may require further soil processing in combination with chemical oxidation or alternative treatment technologies.

\section{SUBJECT TERMS}

Advanced oxidation processes, Chemical oxidation, EPOLAR, Fenton's reagent, Fuel spill cleanup, McMurdo Station (Antarctica), NSF, Soil pollution, Soil remediation, Total petroleum hydrocarbons, United States Antarctic Program

\section{SECURITY CLASSIFICATION OF:}

\section{a. REPORT}

Unclassified

\section{b. ABSTRACT}

Unclassified

\section{c. THIS PAGE}

Unclassified
17. LIMITATION OF ABSTRACT

SAR
18. NUMBER OF PAGES

36 19a. NAME OF RESPONSIBLE PERSON

19b. TELEPHONE NUMBER (include area code) 